\title{
1 Effect of deep cold rolling on mechanical properties and microstructure of nickel-based
}

2 superalloys

3 Balasubramanian Nagarajan ${ }^{1, \mathrm{a}, \mathrm{e}}$, Dharmesh Kumar ${ }^{2, \mathrm{~b}}$, Zheng Fan ${ }^{2, \mathrm{c}}$, Sylvie Castagne ${ }^{2, \mathrm{~d}, \mathrm{fg} \mathrm{g}^{*}}$

$4 \quad{ }^{1}$ Rolls-Royce@ NTU Corporate Laboratory, c/o School of Mechanical \& Aerospace Engineering, 50

5 Nanyang Avenue, Nanyang Technological University, Singapore 639798

$6 \quad{ }^{2}$ School of Mechanical and Aerospace Engineering, Nanyang Technological University, 50 Nanyang

7 Avenue, Singapore 639798

8 abnagarajan@ntu.edu.sg, ${ }^{\text {bdharmesh001@e.ntu.edu.sg } 2{ }_{2}{ }^{2} \text { zfan@ntu.edu.sg, } 0 \text { stagne@ntu.edu.sg }}$

9 (corresponding author)

11 Present address:

12 'Forming Technology Group, Singapore Institute of Manufacturing Technology (SIMTech), Agency

13 for Science, Technology and Research (A*STAR), 73 Nanyang Drive, Singapore 637662

14 fDepartment of Mechanical Engineering, KU Leuven, Leuven, 3001, Belgium

15 'Member Flanders Make, Leuven, Belgium

16

17 Keywords: Mechanical surface treatment, deep cold rolling, nickel-based superalloys, RR1000, IN100, 18 EBSD 


\section{Abstract}

2 Mechanical surface treatments are performed on aerospace components for fatigue life enhancement by 3 introducing beneficial compressive stress profiles and material strengthening. This paper studies the 4 influence of Deep Cold Rolling (DCR) on the residual stress distribution, work hardening and the 5 microstructure modification of two nickel-based superalloys, IN100 and RR1000. Two different 6 diameters $(6.3 \mathrm{~mm}$ and $12.6 \mathrm{~mm})$ of the rolling ball inserts were investigated in this analysis. The 7 hardness and residual stresses at the subsurface after DCR were analyzed along the rolling and transverse directions. Electron BackScatter Diffraction (EBSD) technique was used to characterize the microstructure of the samples both qualitatively and quantitatively. The degree of work hardening of fine grain RR1000 after DCR was characterized using full width at half-maximum (FWHM) of the Xray diffraction peaks and Grain Orientation Spread (GOS) profiles acquired by EBSD characterization.

12 The results clearly indicate that deep cold rolling introduces compressive residual stresses as deep as 1 $\mathrm{mm}$, with significant work hardening at the subsurface in the coarse grain IN100. DCR resulted in the grain refinement, increase in low angle grain boundaries and clustering of dislocation density around the carbides in IN100. Depending on the ball diameter, DCR of RR1000 induced compressive residual stresses up to $700 \mu \mathrm{m}$ and work hardening till the depths of $400 \mu \mathrm{m}$. Additionally, severe deformation of grains occurred near the rolling surface. The larger diameter of the rolling ball resulted in high degree of work hardening and better residual stress distribution deeper into the materials. 


\section{Introduction}

Nickel-based superalloys are the commonly used aerospace materials due to its high temperature strength, oxidation and corrosion resistance [1]. Fatigue life is a critical parameter for the aerospace components, especially the blades and disks, which undergo fatigue loading during operation [2,3]. For fatigue life enhancement, mechanical surface treatments are widely performed to introduce beneficial compressive residual stresses over the subsurface layers and the cold-work induced surface strengthening $[4,5]$. The most common mechanical surface treatment techniques include shot peening, laser shock peening, low plasticity burnishing and deep rolling. The principle of residual stress generation involved in these processes is through plastically-induced misfit, i.e., through non-uniform plastic deformation across the body, whereas the difference between the processes lies in their loading methods, degree of work hardening, surface integrity and the magnitude of residual stress distributions on the surface and subsurface.

Shot Peening (SP) uses spherical balls called shots or projectiles to impact the part surface at high velocities. SP has been traditionally used for nickel-based superalloys including IN718, waspaloy, IN100 and RR1000 [6-13]. Shot peening typically produces highly deformed surface layer, consisting of nanocrystalline structure and high density of statistically distributed dislocations, which improves fatigue life of the components. However, SP typically induces high surface roughness ( $\mathrm{Ra} \sim 4$ to $8 \mu \mathrm{m}$ ) that mandates further finishing [4]. Laser Shock Peening (LSP) is another common surface treatment process for nickel-based superalloys that uses laser-induced shockwaves to impart deformation on the subsurface layers. In comparison to shot peening, LSP typically produces stresses deeper into the material than shot peening with lesser cold work (5 to 7\%) and increased twinning [14-16]. LSP is limited by the poor surface finish and the inability to produce higher stresses on the surface. Conventional roller/ball burnishing and Low Plasticity Burnishing (LPB) use rollers or spherical balls to deform the material surface, which has been employed for the Ni-based superalloys $[14,17,18]$. LPB of IN718 produced deeper and higher compressive stresses and a small degree of cold work (1\%), in comparison to SP and LSP [14].

Deep Rolling (DR) or Deep Cold Rolling (DCR), a process similar to LPB, employs hydrostatically controlled rollers or balls to induce surface and subsurface deformation. The significant process parameters for DCR include rolling pressure, ball diameter, number of passes and the overlap between the two rolling tracks. DCR results in smoother surface, deeper compressive stresses and a moderate cold work than shot peening, while restricting both the crack nucleation and growth [19-21]. Despite a 
1 relatively similar stress profiles at the surface, different studies [4, 22] highlighted that DCR induces

2 high magnitudes of compressive residual stresses deeper into the material, in comparison to other 3 surface treatment methods. An increase in the rolling pressure generally improves the magnitude and 4 depth of compressive residual stresses, surface hardness and surface finish [23]. A similar effect was observed when the ball diameter is increased except that it produced a poor surface finish. Depending on the process variables and the materials, the following microstructure effects were reported after deep rolling: nanocrystalline formation, micro-twins, grain refinement, increase in the dislocation density and dislocation cell structures near the rolled surface [4, 5, 19, 21, 23]. Strain-induced phase transformation to martensite at the near-surface was experienced for austentic stainless steel [24]. However, these studies focused mostly on titanium alloys [19, 21, 22, 25-28], magnesium alloys [22], aluminum alloys [22, 29], austentic steels [24] and plain carbon steels [19, 23]. Despite its advantages, deep cold rolling of nickel-based superalloys has hardly been studied previously, especially at a microstructural level [30, 31].

This paper investigates the influence of deep cold rolling on two nickel-based superalloys, IN100 and RR1000, using two different diameters of the rolling ball. Hardness and residual stresses at the surface and the cross-section were analyzed to understand the effects of DCR on the mechanical properties of the materials. Microstructure effects by DCR has been studied quantitatively and qualitatively using different characterization techniques including Optical Microscope (OM), Scanning Electron Microscope (SEM) and Electron BackScatter Diffraction (EBSD).

\section{Experiments and Methodology}

Table 1 indicates the chemical compositions of IN100 and RR1000 which are investigated in this study. IN100 had undergone investment casting followed by hot isostatic pressing in Argon gas environment for $4 \mathrm{~h}$ at $103 \mathrm{MPa}$ and a temperature of $1220{ }^{\circ} \mathrm{C}$. Fine Grain (FG) RR1000 is a powder metallurgy alloy that was forged, then solution-annealed and aged at $760{ }^{\circ} \mathrm{C}$ for $16 \mathrm{~h}$ and was provided by RollsRoyce plc. RR1000 has been used predominantly for turbine discs [8, 32]. Both RR1000 and IN100 contains a large volume fraction of $\gamma^{\prime}$ precipitates along with a fine distribution of carbides, as seen from Fig. 1. The average grain size of as-received RR1000 samples was measured to be $5.4 \mu \mathrm{m}$. IN100 microstructure contains $\gamma$ matrix with the austentic grain size greater than $200 \mu \mathrm{m}$ with a fine dispersion of $\gamma^{\prime}$ precipitates of size less than $2 \mu \mathrm{m}$. The typical yield strength of RR1000 and IN100 are 
$11050 \mathrm{MPa}$ [33] and $1018 \mathrm{MPa}$ [1] at room temperature, respectively. Flat test coupons with a thickness 2 of $10 \mathrm{~mm}$ and $20 \mathrm{~mm}$ respectively for RR1000 and IN100 were used during the DCR study.

Table 1. Chemical composition of IN100 and RR1000

\begin{tabular}{lllllllll}
\hline & $\mathrm{Ni}$ & $\mathrm{Co}$ & $\mathrm{Cr}$ & $\mathrm{Al}$ & $\mathrm{Ti}$ & $\mathrm{Mo}$ & $\mathrm{C}$ & Others \\
\hline IN100 & 60 & 15 & 10 & 5.5 & 4.7 & 3 & 0.15 & $1 \mathrm{~V}, 0.06 \mathrm{Zr}, 0.015 \mathrm{~B}$ \\
\hline RR1000 & 52.3 & 18.5 & 15 & 3 & 3.6 & 5 & 0.027 & $2 \mathrm{Ta}, 0.06 \mathrm{Zr}, 0.015 \mathrm{~B}, 0.5 \mathrm{Hf}$ \\
\hline
\end{tabular}

5

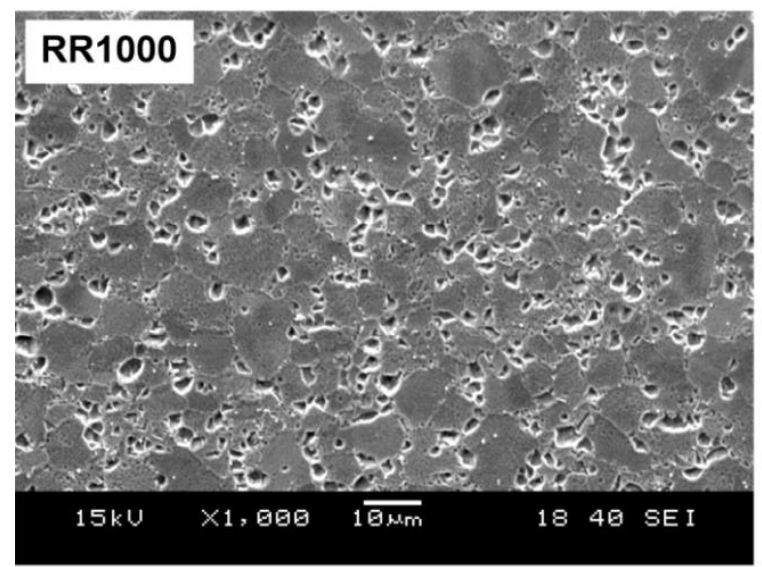

(a)

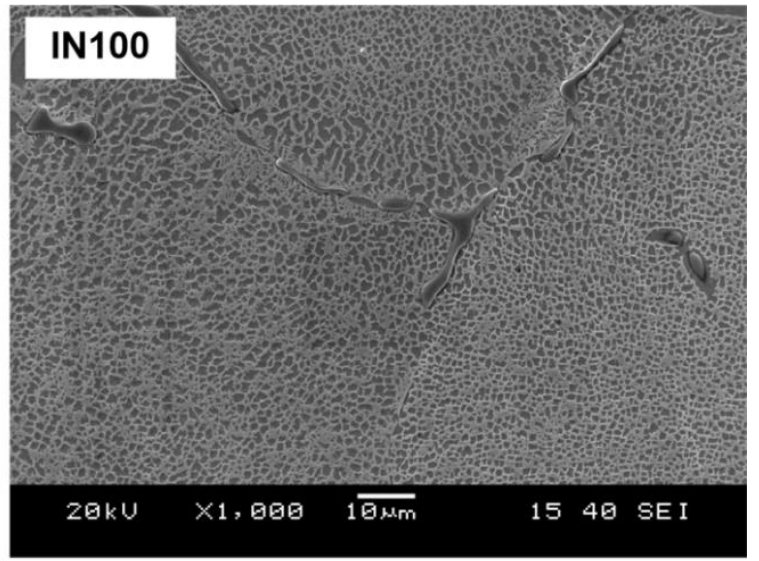

(b)
6

Fig. 1. SEM micrograph of the microstructure of (a) RR1000 and (b) IN100

Deep cold rolling experiments on RR1000 and IN100 were performed with the hydrostatically controlled spherical balls supplied by ECOROLL AG Werkzeugtechnik. The DCR tool was attached to a robot head through special fixtures that moves along the longitudinal direction during the process. DCR experiments were tested using two ceramic ball diameters, $6.35 \mathrm{~mm}$ and $12.7 \mathrm{~mm}$, which are specified as HG6 and HG13 respectively. The rolling pressure of 100 bar and 400 bar was used for RR1000 and IN100, respectively. Different rolling pressures were used due to the differing initial surface state of the as-received materials that had undergone different process routes. A constant overlap of $200 \%$, which represents the passing of the tool three times over the same intended area, was used for both the materials.

7 The rolled samples were examined along the rolling (longitudinal) and transverse directions at the cross-section after wire-cutting, grinding, rough and final polishing. The polished samples were then etched using Kallings No.2 reagent $\left(40 \% \mathrm{HCl}, 60 \%\right.$ Methanol and $2 \mathrm{~g}$ of $\mathrm{CuCl}_{2}$ ) for $20 \mathrm{~s}$ and 70 s to reveal the microstructures of RR1000 and IN100, respectively. 
1 Vickers microindenter was used to measure the hardness at the surface and the cross section of the samples using 500g load. Two successive indentations along the cross-section were sufficiently spaced to avoid the interacting effects. An average hardness of 10 and 4 measurements in the surface and cross-section respectively has been used in the analysis.

5

Residual stresses of FG RR1000 were measured using the XRD $\sin ^{2} \psi$ method. Stresstech Xstress G3 X-Ray Diffraction (XRD) system with the Mn K $\alpha$ radiation $(\lambda=2.10314 \AA$ ) was used to measure the

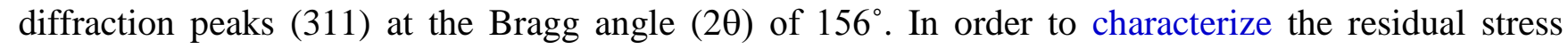
measurements in the depth, electropolishing was performed using $92 \%$ methanol and $8 \%$ perchloric acid mixture as electrolyte for the layer removal. XRD measurements were conducted along the rolling and transverse directions at each depth levels. No correction for the layer removal and stress gradient was performed for the residual stress measurements. The diffraction peak broadening characterized by the full-width at half maximum (FWHM) is considered as an indicator of microstrain associated with the cold working [34]. FWHM of XRD peaks has been used extensively to characterize the work hardening after the surface treatment processes $[6,12,14]$ and is employed in this study to characterize the work hardening associated with RR1000 after deep cold rolling.

XRD measurements could not be used for IN100 due to the peak splitting associated with the coarse grain structure. So, the residual stress measurements of as-received and deep cold rolled IN100 samples were conducted using Center Hole Drilling (CHD) technique by Stresscraft Ltd, in accordance with ASTM E837-13a. CHD evaluates the residual stresses from the relaxed strains after incremental drilling steps using the integral method [35]. Vishay Precision Group type EA-06-062RE-120 strain gauge was bonded on the sample surface to record the relieved strains. Orbital hole drilling was carried out at 16 increments till $1024 \mu \mathrm{m}$ depth. The diameter of the hole was $1.9 \mathrm{~mm}$. The measurement uncertainties in the hole drilling method due to the strain gauge and indicator are estimated to be \pm 61 $\mathrm{MPa}$ at the depths between 16 to $112 \mu \mathrm{m}, \pm 11 \mathrm{MPa}$ at depth $512 \mu \mathrm{m}$ and $\pm 25 \mathrm{MPa}$ at $1064 \mu \mathrm{m}$. The other factors including the component, drilling process and measurement procedure contribute an additional $7 \%$ uncertainty to the measured stress values.

Microstructure analysis of the materials was performed using JEOL Scanning Electron Microscope (SEM). Electron BackScatter Diffraction (EBSD) technique was used for the qualitative and quantitative microstructure characterization. A HKL backscattered detector attached to JEOL JSM $7600 \mathrm{~F}$ system was used for acquiring the EBSD patterns. The EBSD datasets were collected using AZTEC HKL package at a frame rate of 512 fps over an area of $250 \times 200 \mu \mathrm{m}$ from the rolled edge. A 
1 step size of $0.4 \mu \mathrm{m}$ was used for all the conditions. The samples after 15 mins of final polishing by 2 colloidal silica suspension $(0.04 \mu \mathrm{m}$ size $)$ were used for the EBSD analysis. EBSD dataset was 3 analyzed using Oxford instruments' Tango Maps software package. Filtering of the wild spikes and 4 low-noise was applied on the acquired images. Misorientation angles of $15^{\circ}$ and $2^{\circ}$ were used to define 5 the grain and subgrain boundaries respectively. This analysis uses Inverse Pole Figure (IPF) and band contrast maps to compare the microstructure modification before and after DCR.

7 Evaluation of plastic strain using EBSD has been demonstrated by various researchers to characterize 8 the plastic deformation [6, 8, 12, 36, 37]. Residual strain in the material can be evaluated using the EBSD pattern quality or the local misorientation [38, 39]. Foss et al. [6] compared Grain Mean Misorientation (GMM), an average misorientation between each neighboring pair of measurement points within the grain, between the as-peened and post-treatment RR1000 samples to evaluate the work hardening. Child et al. [12] used the Grain Orientation Spread (GOS) parameter, which is measured as the average deviation in orientation between every pixel in a grain with the average grain orientation, to quantitatively evaluate the depth of the work-hardened/coldwork layer after shot peening of Udimet 720Li. This methodology has been employed to study the plastic deformation of different materials and surface treatment processing $[6,8,40]$. This paper uses GOS profiles to characterize the plastic deformation after deep rolling of RR1000 quantitatively. The GOS value for each grain is first sorted according to the y-axis (along the depth). Then the moving average of GOS over 100 grains was calculated and plotted against the distance from the rolled surface. The bulk GOS was averaged over the grains exist between 100 and $200 \mu \mathrm{m}$. The depth of work hardening zone is estimated by the depth at which GOS moving average curve intersects with the bulk GOS. In addition, Local Misorientation (LM) data, the average misorientation of a pixel with its nearest neighboring points, has been compared to understand the variation in misorientation within the grains.

\section{Results and discussions}

\section{1. $\quad$ Surface hardness}

Fig. 2 illustrates the effect of deep cold rolling on the surface hardness of IN100 and RR1000. The results evidently indicate a surface hardening in both the materials after DCR. IN100 experienced a $50 \%$ increase in hardness, along with a higher standard deviation after rolling. The surface hardening of RR1000 after DCR is much lesser (10\%) but with better uniformity, in comparison to IN100. An insignificant difference in hardening between the different ball sizes is noted for IN100 (Fig. 2), which 
1 could be due to the high standard deviation. However, for RR1000, the larger ball (HG13) resulted in a 2 slightly lesser hardening. Hassan et al. [41] observed a similar behavior of reduction in hardness with 3 an increase in ball diameter during ball burnishing of brass and $\mathrm{Al}-\mathrm{Cu}$ alloy. This behavior was 4 attributed to the increase in contact area with the larger ball diameter, causing deeper penetration under 5 the same burnishing force with lesser plastic deformation [41]. Contrastingly, a larger ball diameter was found to induce higher surface hardness in IN718 [18]. Larger ball also induced higher and deeper compressive stresses in stainless steel and IN718 [23, 42] due to higher burnishing force and the increased coverage [43]. Several experimental and numerical studies highlighted the occurrence of the maximum effective stress at the subsurface $[5,20,43]$ according to Hertzian contact theory. In addition, work softening of the surface layers was experienced for certain materials after rolling [4, 20]. In order to understand the observed behavior with the varying ball diameter, the strain hardening at the subsurface should be examined. The observed difference in surface hardening behavior between RR1000 and IN100 can be attributed to the lesser rolling pressure used for RR1000 and the initial work 14 hardening state of the as-received RR1000 samples.

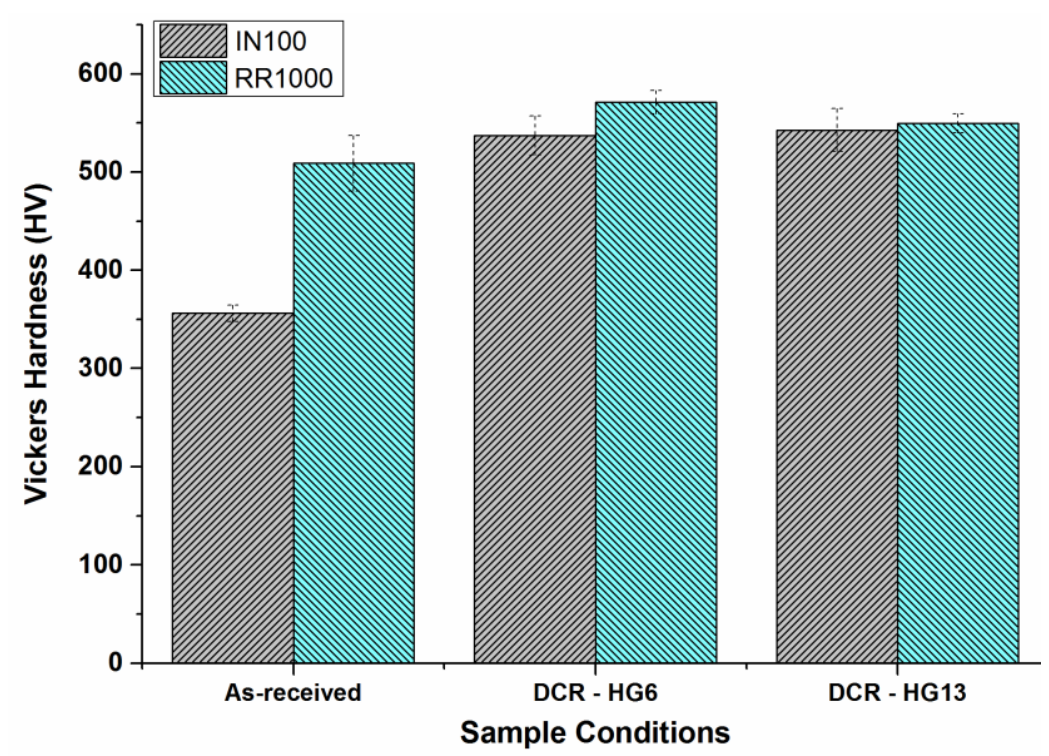

Fig. 2. Effect of deep cold rolling on the surface hardness of RR1000 and IN100

\subsection{Cross-sectional hardness}

Fig. 3 compares the hardness distribution along the depth at the rolling and transverse directions before and after deep cold rolling of IN100 and RR1000, using two different ball diameters. Four hardness measurements were performed at every $50 \mu \mathrm{m}$ depth increment and the average values along with standard deviation are plotted. 
1 It can be observed from Fig. 3a that hardness of the as-received IN100 varies between 356 and 396 HV

2 across the sample thickness consistently. Fig. 3a clearly indicates the significant increase in hardness

3 after DCR along the depth. At $500 \mu \mathrm{m}$ depth, the difference in hardness between the as-received and

4 deep cold rolled IN100 samples is 10\% and 38\% for HG6 and HG13, respectively. At a deeper

5 thickness of $750 \mu \mathrm{m}, \mathrm{HG} 13$ ball produced a 15\% increase in hardness whereas HG6 induced no further

6 strengthening. The cross-sectional hardness profile is consistent for both the ball diameters as the

7 hardness increased gradually from the rolled surface along the depth till a peak value is reached.

8 However, the depth at which the peak hardness occurred was also deeper with HG13 ball (300 $\mu \mathrm{m})$

9 against 150 to $200 \mu \mathrm{m}$ for HG6. The results clearly indicate that the hardening behavior for IN100

10 agree with the previous studies where a high degree of plastic deformation was experienced with the

11 larger ball diameters [23, 42, 43]. The hardening effect, inclusive of parameters such as peak hardness

12 and its depth and the hardening zone, indicates only a minor variation between rolling and transverse

13 directions.

14

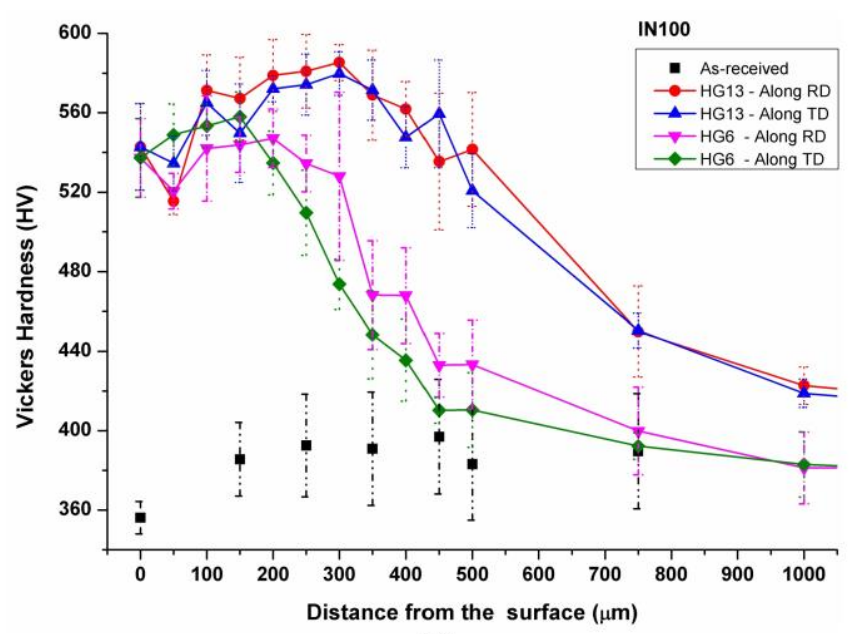

(a)

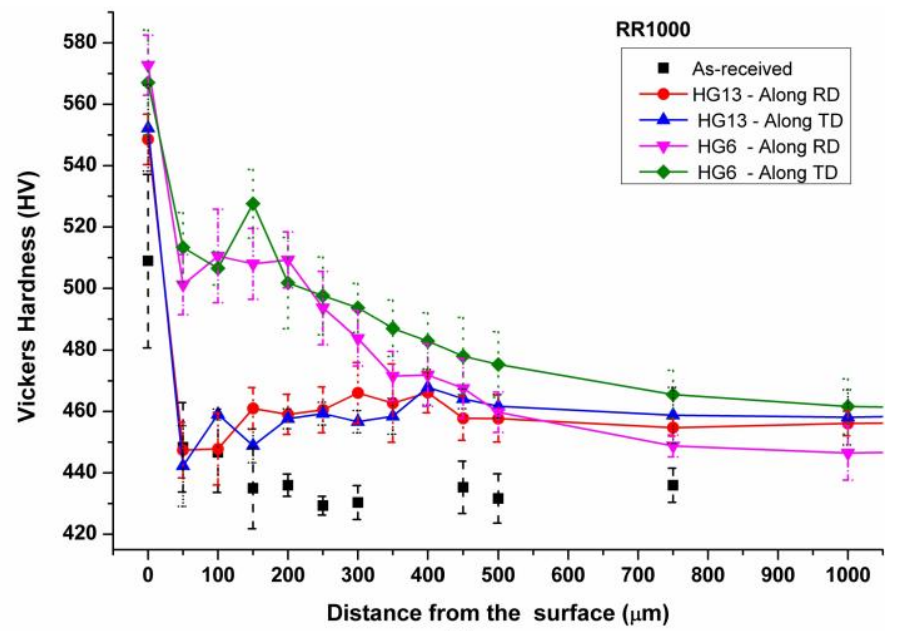

(b)

Fig. 3. Effect of deep cold rolling on the hardness along the depth of (a) IN100 and (b) RR1000

Deep cold rolling of RR1000 shows a different hardening trend, as seen clearly in Fig. 3b. Contrary to the occurrence of the peak hardness at the subsurface for IN100, RR1000 has the maximum hardness at the surface for all the sample conditions. The hardness values of the as-received RR1000 clearly indicates a pre-existing work hardening up to $100 \mu \mathrm{m}$. DCR with the HG13 ball resulted in a hardness profile similar to the as-received state till $100 \mu \mathrm{m}$ depth. At further depths up to $750 \mu \mathrm{m}$, the hardness increase varies between 4.3 and 8.3\%. However, the samples after DCR with HG6 ball experienced a consistently higher hardening that ranges from 7 to $21 \%$ for the similar depths. Hardening at the 
1 surface and subsurface is more prominent with the HG6 ball, as evident from Fig. 3b. Similar to IN100,

2 no significant difference is noticed between the rolling and transverse directions. It can be noticed that 3 the DCR ball diameter effect on the hardness behavior of RR1000 (Fig. 3b) has been contradictory to 4 IN100, where larger ball produced higher and deeper stresses (Fig. 3a). This behavior could be due to 5 the corresponding residual stress distribution or the microstructure modifications at the corresponding depth which will be investigated in the following sections.

7 Though the hardness measurements are used vastly to understand the effect of work hardening, it has been reported by various researchers $[6,12]$ that the residual stress distribution in the material too influences the hardness values significantly. As the deep cold rolling introduces compressive residual stresses along the subsurface in addition to the work hardening, the individual effects on the hardness behavior needs to be isolated through the measurement of residual stress profiles after rolling. Another limitation with the microhardness measurements in this analysis has been its inability to measure the hardness for depths smaller than $50 \mu \mathrm{m}$ in order to avoid the edge effects. However, it has been reported in the literature that significant microstructure changes occur at depths less than $50 \mu \mathrm{m}$ after surface treatment of many materials $[4-6,8,12,19]$.

\subsection{Residual stresses}

Fig. 4 compares the residual stress depth profiles before and after DCR of IN100 and RR1000 along the rolling and the transverse directions. The surface residual stress, compressive stress region, peak residual stress and its corresponding depth are the commonly used parameters to evaluate the residual stress distribution after surface treatment processes.

Fig. 4a illustrates the residual stresses along the depth of IN100 before and after DCR, measured by center hole drilling (CHD) method. As the stresses could not be measured on the surface using the CHD method, the stresses at the nearest measurement depth of $16 \mu \mathrm{m}$ is considered as the surface stresses for this analysis. The as-received IN100 samples are found to have compressive stresses close to the surface within 100 to $150 \mu \mathrm{m}$. No stresses are observed for the depths further than $150 \mu \mathrm{m}$, as seen in Fig. 4a. The surface stresses after DCR are found to be less compressive than the as-received condition. The reduction in ball size from HG13 to HG6 resulted in an increase in surface compressive residual stresses along both the rolling and transverse directions. Similarly, HG6 ball introduced higher peak residual stresses along the rolling direction but with slightly lesser stresses along the transverse direction. However, the depth at which the peak stress occurred is found to be deeper with HG13 ball 
$1(250 \mu \mathrm{m})$ in comparison to HG6 $(160 \mu \mathrm{m})$. It is found from Fig. 4a that DCR of IN100 introduced 2 compressive residual stresses for depths more than $1 \mathrm{~mm}$ at all processing conditions. No transition to 3 the tensile stress region occurred for the measurement depth till $1.06 \mathrm{~mm}$. It can be noted that DCR with HG13 ball resulted in tensile surface stress along TD, despite having higher stresses deep into the material (peak stress depth at $300 \mu \mathrm{m}$ ). As the larger ball (HG13) along with the high pressure (400 bar) is expected to induce high plastic deformation, possible severe microstructure alteration very close to the surface layers could have resulted in the relaxation of stresses during rolling. The stress levels higher than the yield stress with HG6 along the transverse direction could be due to the measurement error with the CHD method. Residual stress profile after DCR with the same HG6 ball but with a lesser pressure of 200 bar was compared (not shown in this paper), which produced peak stresses lesser than the yield stress.

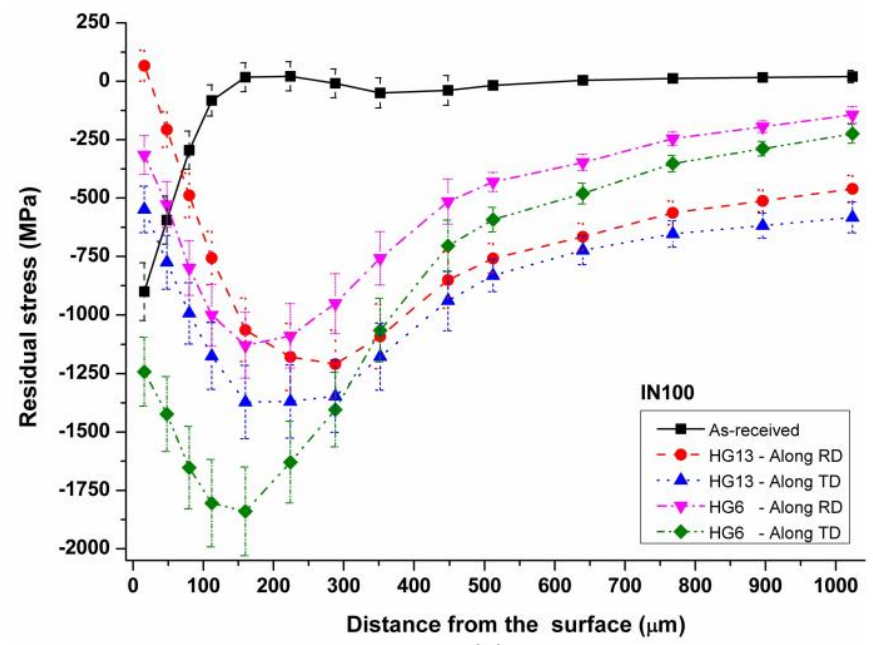

(a)

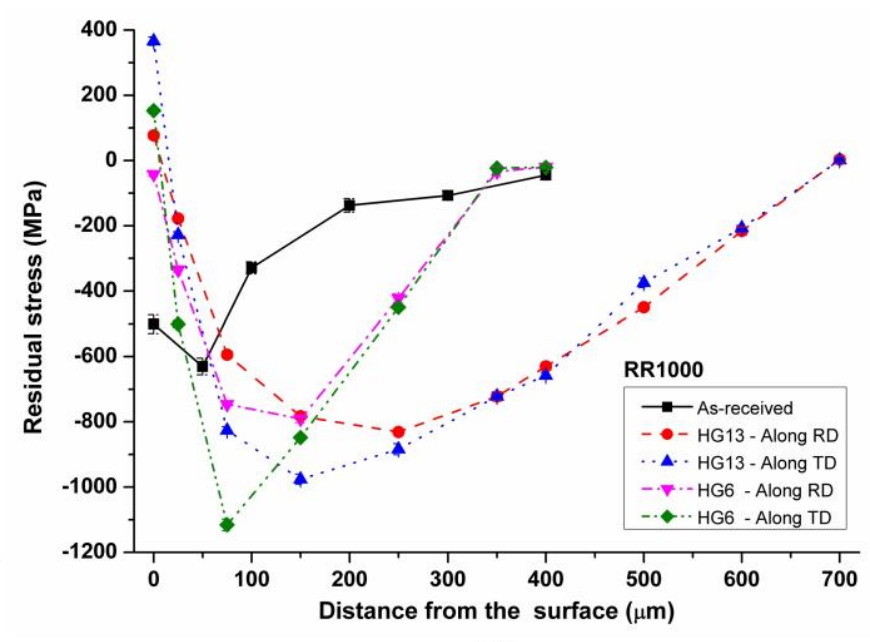

(b)

Fig. 4. Effect of DCR on the residual stress distribution along the depth on (a) IN100 and (b) RR1000

It can be noted from Fig. 4b that the as-received RR1000 samples have compressive stresses up to 300 $\mu \mathrm{m}$ approximately. The pre-existing compressive stresses and work hardening of the as-received samples (as seen from Fig. 3b) could explain the tensile surface stresses of RR1000 after DCR. It is obvious from Fig. 4b that the HG13 ball induced higher and deeper compressive stresses than HG6. HG13 ball produced deeper penetration of compressive stresses up to $700 \mu \mathrm{m}$ in comparison to $350 \mu \mathrm{m}$ by HG6 ball. The stresses are found to be slightly higher along the transverse direction. 


\section{3.4. Microstructure characterization.}

\subsubsection{Effect of DCR on IN100 microstructure}

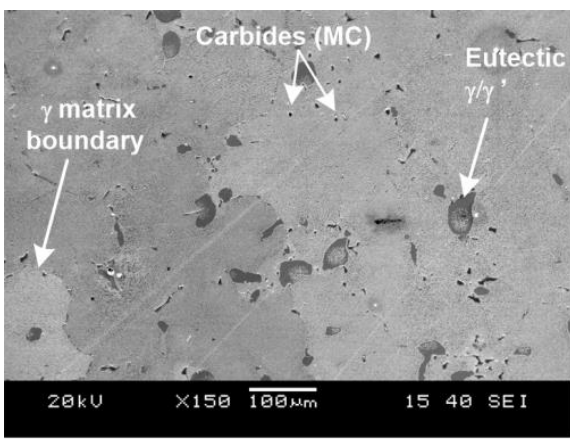

(a)

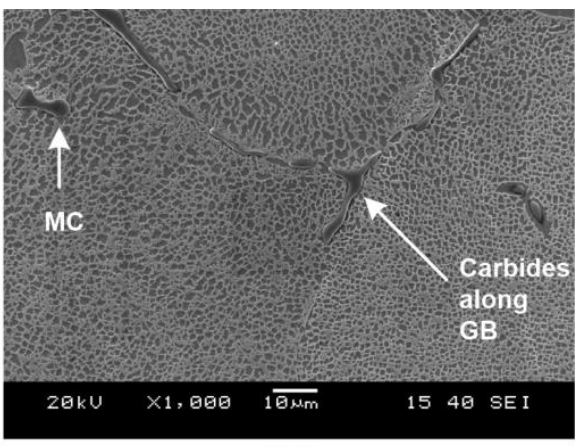

(b)

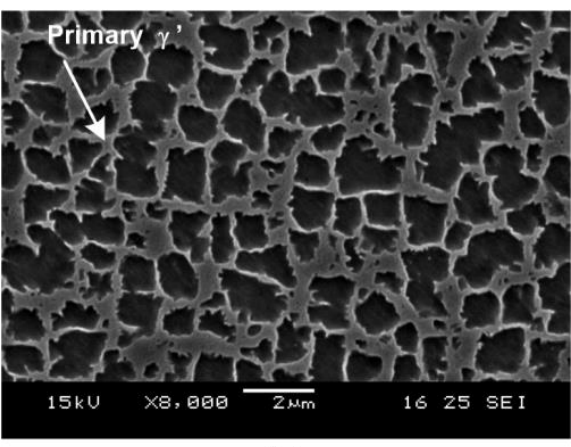

(c)

Fig. 5. SEM micrographs of the as-received IN100 samples at different magnifications (a) 150x (b)

$$
\text { 1000x (c) 8000x }
$$

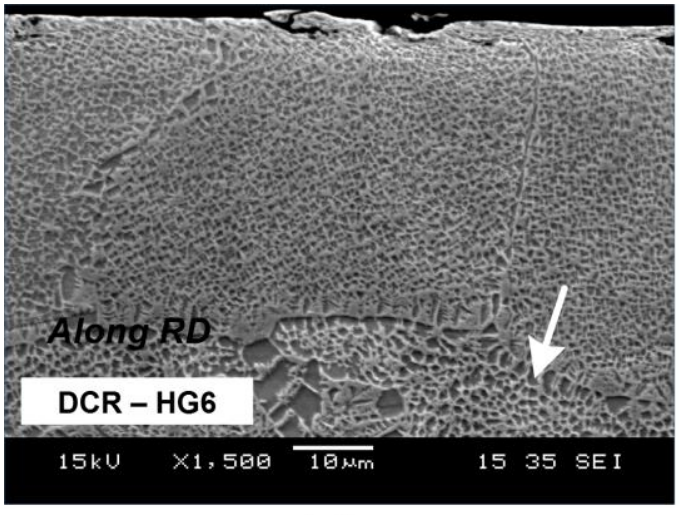

(a)

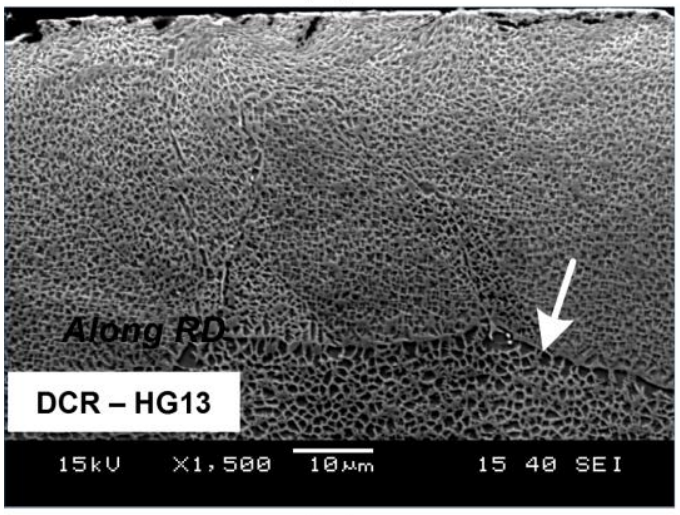

(c)

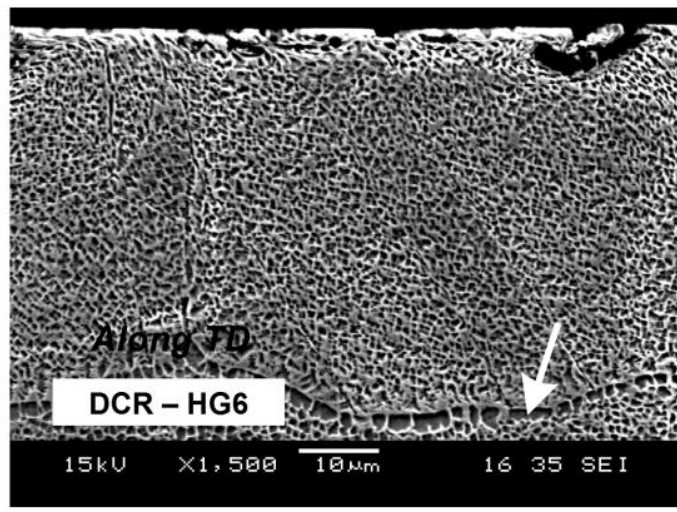

(b)

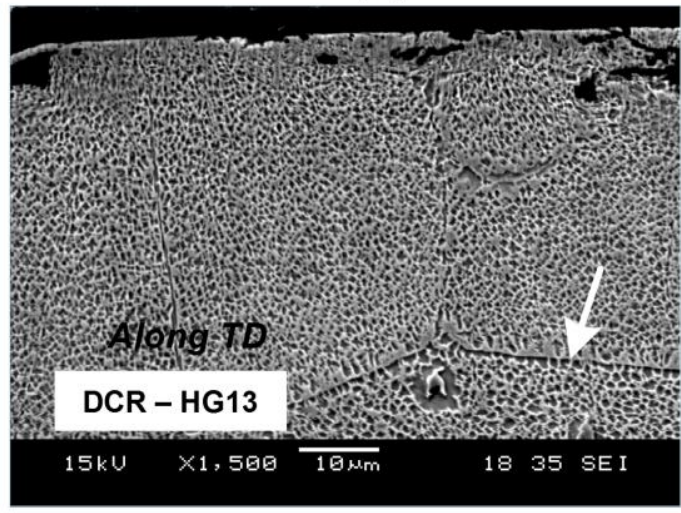

(d)

Fig. 6. Comparison of IN100 microstructure after DCR with (a, b) HG6 ball and (c, d) HG13 ball, along the rolling direction (left) and transverse direction (right) 
1 Fig. 5 shows the microstructure of IN100 consisting of coarse $\gamma$ matrix, $\gamma$ ' precipitates, eutectic $\gamma / \gamma^{\prime}$ 2 and fine dispersion of carbides within the matrix and the along the grain boundaries. The austenitic 3 grain size of the $\gamma$ matrix is greater than $200 \mu \mathrm{m}$, as observed through $\gamma$ boundary in Fig. 5a. $\gamma^{\prime}$ 4 precipitates of size less than $2 \mu \mathrm{m}$ are finely dispersed within the $\gamma$ matrix as seen in Fig. 5c.

5 Fig. 6 compares the microstructure of deep cold rolled IN100 between the two different ball diameters 6 along the rolling and transverse directions. It is evident that the grains at the top surface layer had 7 experienced a severe compression after rolling. The coarser as-received grains were compressed into 8 the size ranging between 40 and $50 \mu \mathrm{m}$ during the rolling, which is marked by the white arrows along

9 the interface between the top and bottom layers in Fig. 6. The $\gamma^{\prime}$ precipitates very close to the rolled surface are found to experience a significantly high distortion. Fig. 6 indicates that the IN100 11 microstructure after DCR has been quite consistent across the HG6 and HG13 balls. Similarly, no significant difference in the microstructure was observed between the rolling and transverse directions.

(b)

(a)

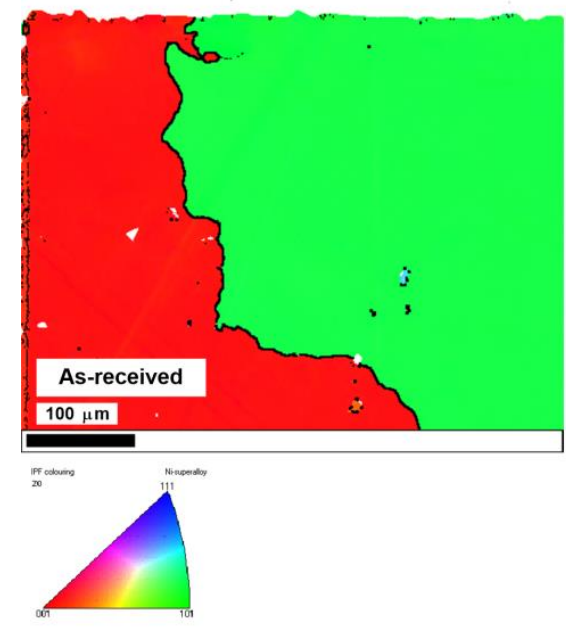

13

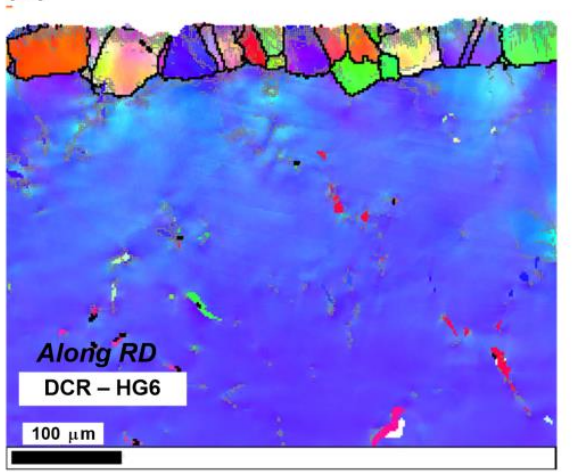

(d)

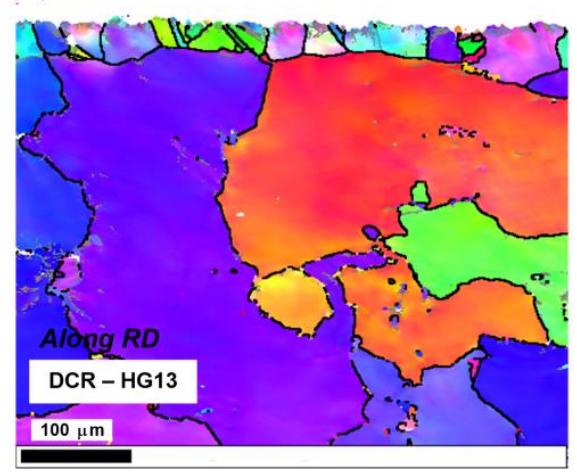

(c)

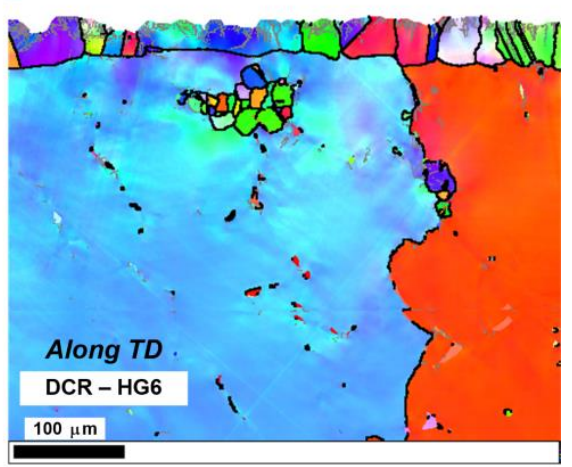

(e)

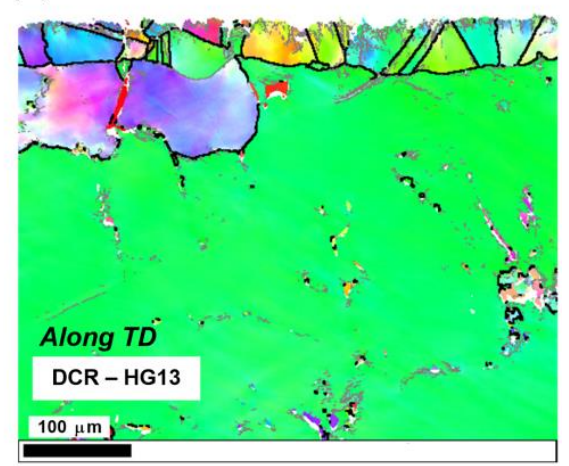

Fig. 7. Effect of DCR on EBSD Inverse Pole Figure (IPF) maps of IN100: (a) as-received, (b, c) DCR with HG6 ball along RD and TD and (d, e) DCR with HG13 ball along RD and TD 
1 Fig. 7 and 8 illustrate the EBSD inverse pole figure (IPF) maps and the band contrast (BC) maps of 2 IN100 respectively, in which the as-received samples are compared with the rolled samples. It is 3 obvious from Fig. 7a that the as-received samples are devoid of any pre-existing cold working, as confirmed by the coarse grains larger than $200 \mu \mathrm{m}$. EBSD maps (as seen from Fig. $7 \mathrm{~b}$ to $7 \mathrm{e}$ ) indicate a severe compression of the grains along the rolling surface. The heavily deformed grains during DCR lead to grain refinement, as seen in the top layer closer to the rolled surface. The average grain size of this top deformed layer has been approximately $50 \mu \mathrm{m}$. Another common feature between all the rolled samples has been the formation of twin boundaries during the deformation (Fig. $7 \mathrm{~b}$ to $7 \mathrm{e}$ ). Pole figure maps (not presented in this analysis) indicated no significant texturing after DCR.

(c)

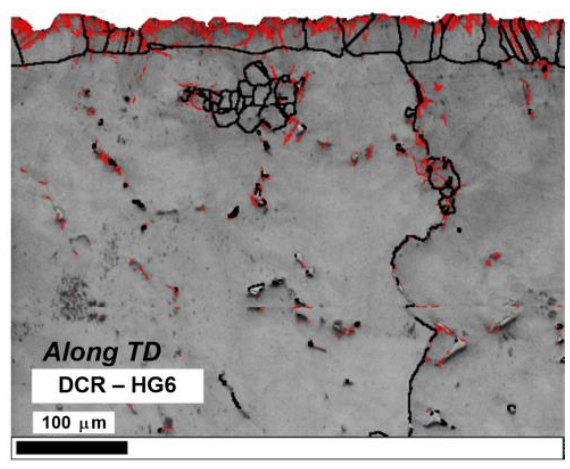

(e)

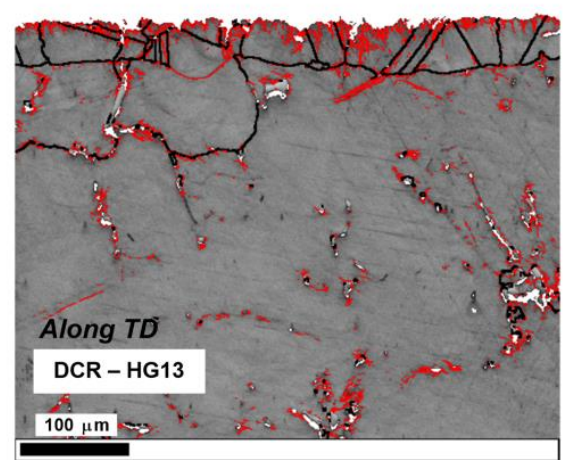

(b)

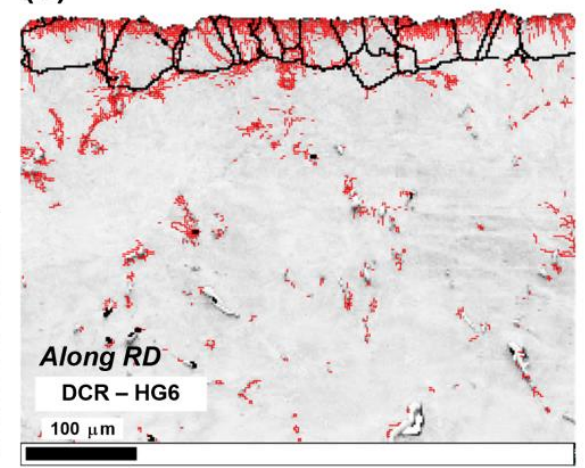

(d)

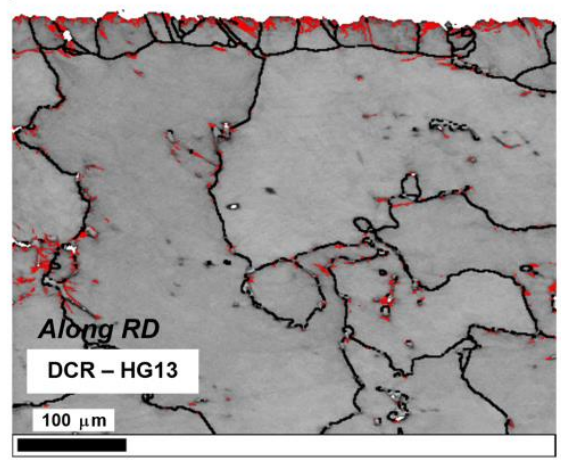

(a)

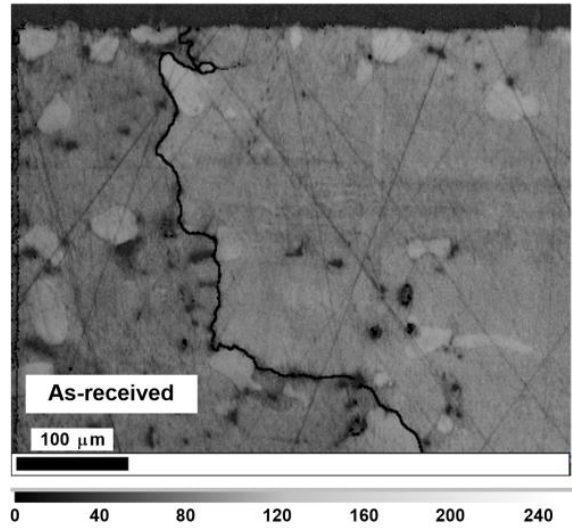

Fig. 8. Effect of DCR on EBSD band contrast maps of IN100: (a) as-received, (b, c) DCR with HG6 ball along RD and TD and (d, e) DCR with HG13 ball along RD and TD

The band contrast maps (Fig. 8) show the low angle and high angle grain boundaries of the as-received and rolled samples. The low angle grain boundaries (LAGB) with the misorientation angles between $2^{\circ}$ and $15^{\circ}$ are indicated as red lines in the maps. A significant increase in the number of low angle grain boundaries can be noted after rolling, which gives an indication of the increase in dislocation density. A large number of LAGBs was observed in the subsurface region immediately closer to the surface, due 
1 to the obviously high degree of plastic deformation. High concentration of LAGBs is typically 2 indicative of concentrated geometrically necessary dislocation (GND) density regions. The formation 3 of GNDs correspond to the dislocation cell structures, which is a common occurrence with deep rolling 4 [5]. A large number of LAGBs, hence the dislocations, were found to cluster around the fine carbides at 5 thicknesses deeper into the material. A similar accumulation of such dislocations around the carbides 6 has been reported earlier in RR1000 [8] and AISI4140 [5] during shot peening.

7 It can be identified from Fig. 8 that there is no significant difference in the microstructure between the 8 rolling and transverse directions, as similar to the corresponding hardness profiles (Fig. 3). For DCR with HG6 ball, only the top layer of grains experienced a compression, as seen from Fig. 8b and 8c. However, HG13 ball resulted in the compression of the subsequent layer of grains too, as evident from 11 Fig. 8d and 8e, due to the higher rolling force associated with the larger balls. This observed behavior matches with the higher and deeper hardness profiles along the cross section of the material after DCR with HG13 (Fig. 3). The excessive deformation with larger rolling balls could have resulted in the relaxation of residual stresses causing tensile surface stresses (as seen in Fig. 4a).

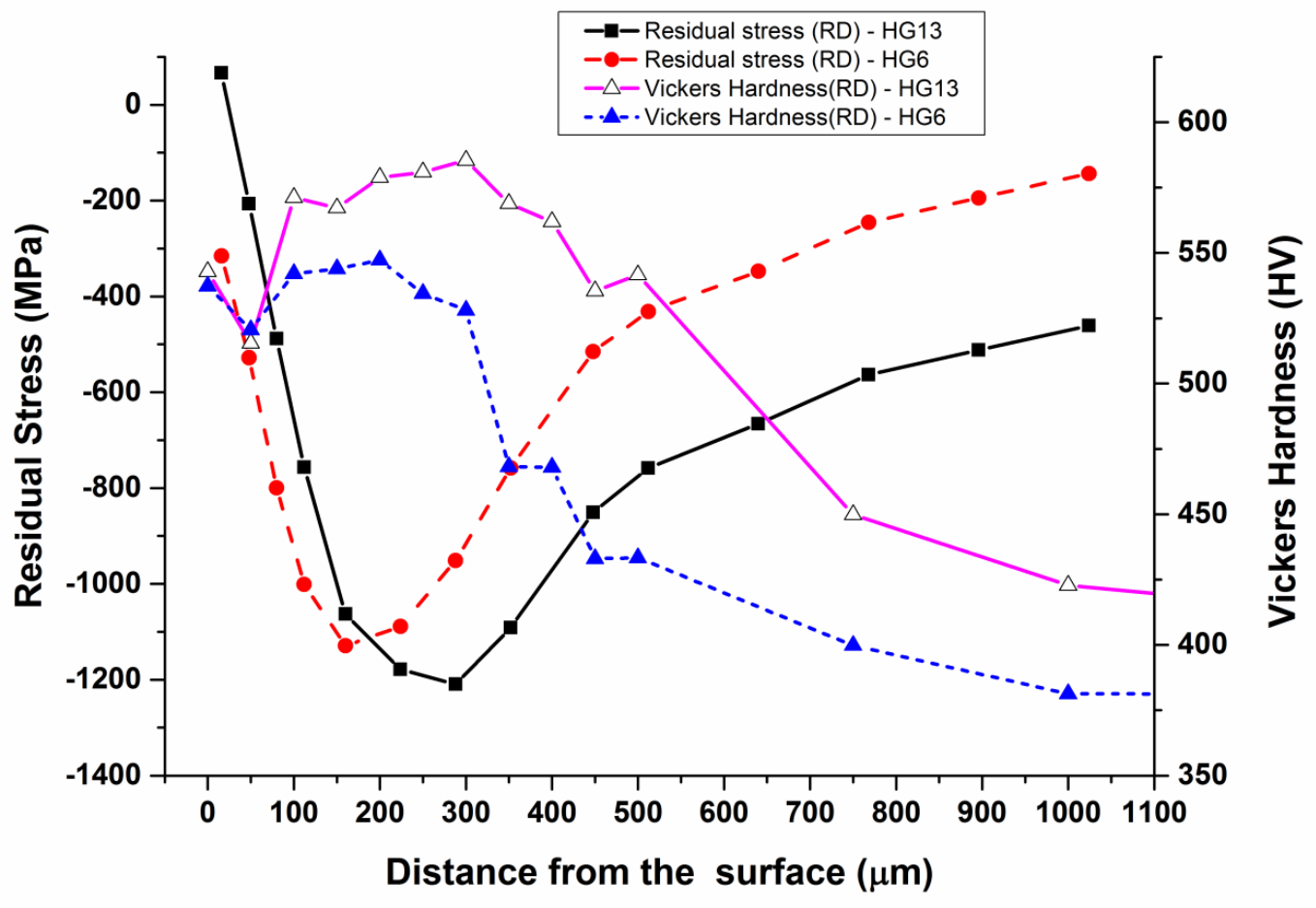

Fig. 9. Comparison of residual stress distribution and hardness along the depth in IN100 after DCR It should be noted that the region very close to the surface rolled with HG13 could not be indexed due to the highly distorted EBSD patterns. A similar a behavior has been reported previously for severe 
1 plastic deformation of shot peened RR1000 [8]. Despite underestimating the work hardening zone,

2 non-indexed regions provide an indication of the severity of plastic deformation in the specified 3 regions.

4 Fig. 9 compares the cross-section hardness profile with the residual stress distribution of IN100 after 5 DCR along the rolling direction. It can be deduced from Fig. 9 that the peak values of the compressive 6 stress and hardness occurred at the similar depths. The further reduction in hardness and compressive 7 residual stress along the depth tends to follow a similar behavior. This trend indicates the predominant 8 effect of residual stress on the hardness values, in comparison to work hardening effect. It is understandable as the grain refinement and sever plastic deformation occurs only within 40 to $50 \mu \mathrm{m}$ during DCR in IN100. At the further depths, the effect of work hardening can be perceived by the dislocations clustering round the carbides. Due to the coarse grain structure and wide dispersion of the carbides with IN100, the hardness measurements could be unable to account for the dislocation effects occurred deeper into the material.

\section{3.4.2. Effect of DCR on RR1000 microstructure}

The influence of DCR on the RR1000 microstructure was investigated using the EBSD technique in this analysis. Fig. 10 compares the band contrast maps of RR1000 before and after DCR along the rolling and transverse directions. It is evident from Fig. 10 that no significant grain refinement occurred at the near-surface region after DCR. Fig. 11 illustrates the grain size distribution of RR1000 after DCR. It can be realized that grains with diameter lesser than $1 \mu \mathrm{m}$ exist in a similar proportion for all the sample conditions before and after DCR. An increase in the proportion of grains with diameters between 1 to $2 \mu \mathrm{m}$ can be noticed between the as-received and the rolled samples. No significant difference in the grain size was noticed for the samples rolled with either HG6 or HG13 ball diameters. Formation of low angle grain boundaries is largely absent with DCR of RR1000 (Fig. 10), unlike in IN100 (Fig. 8). This behavior can be explained by the fine grains of RR1000 where the dislocation movement during deformation will be intercepted by the grain boundaries, whereas carbides impede the dislocations in IN100. 
(b)

(a)

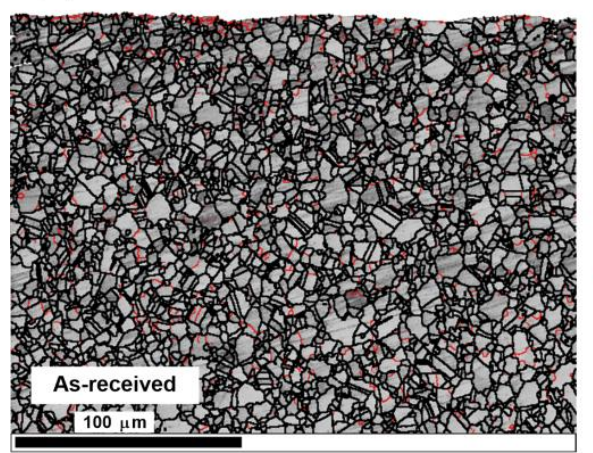

\begin{tabular}{llllll}
\hline 0 & 40 & 80 & 120 & 160 & 200
\end{tabular}

(d)
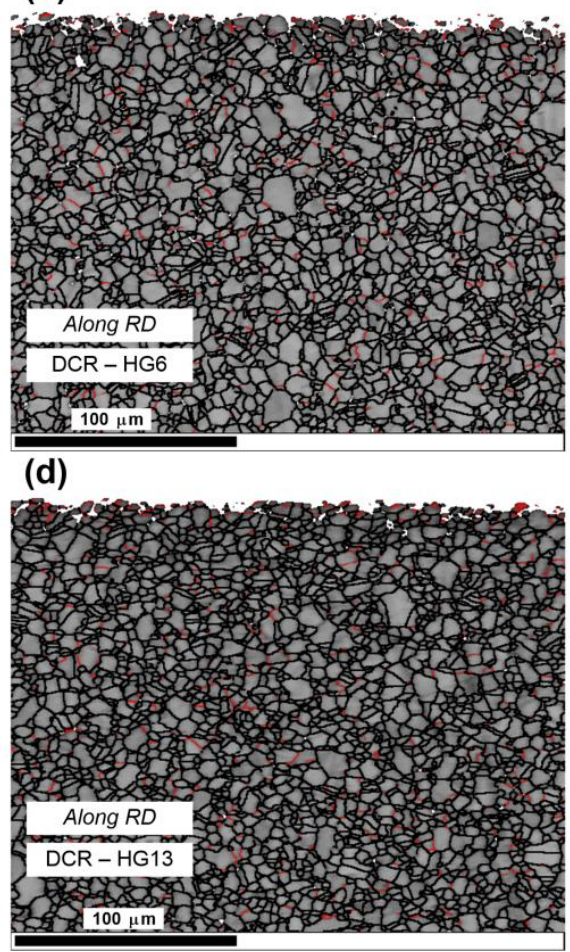

(c)

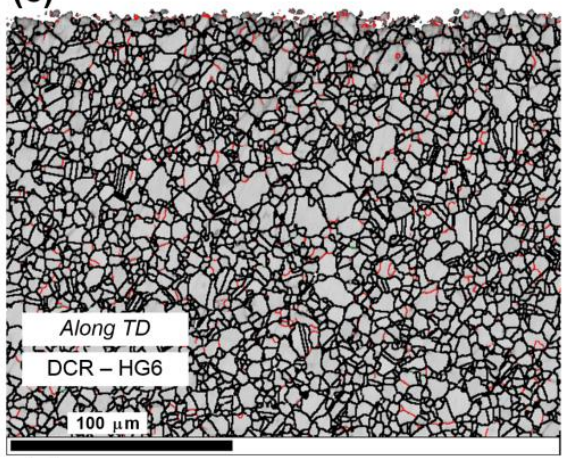

(e)

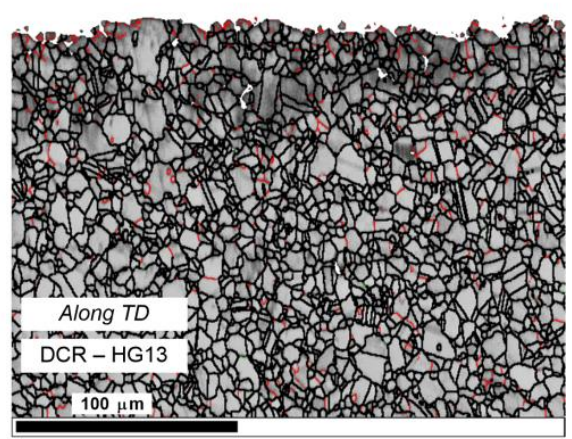

2 Fig. 10. Effect of DCR on EBSD band contrast maps of RR1000: (a) as-received, (b, c) DCR with HG6 ball along RD and TD and (d, e) DCR with HG13 ball along RD and TD

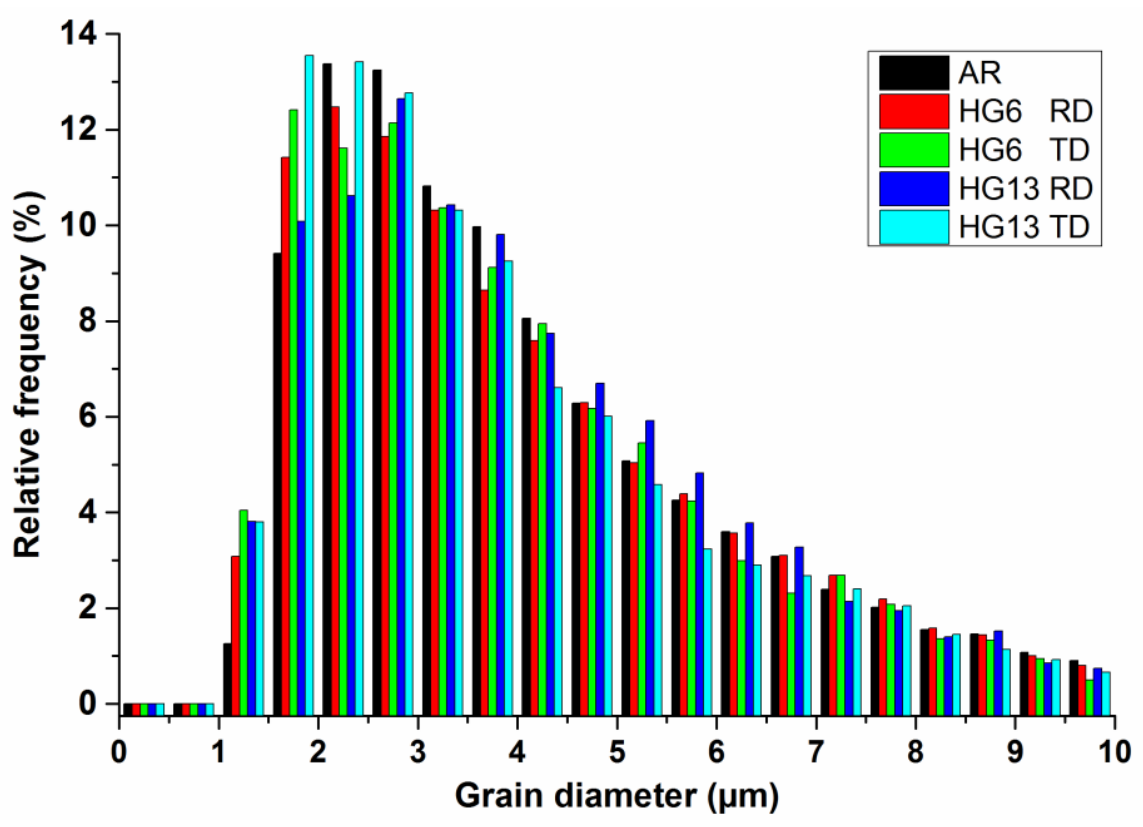

Fig. 11. Effect of deep cold rolling on the grain size distribution of RR1000 

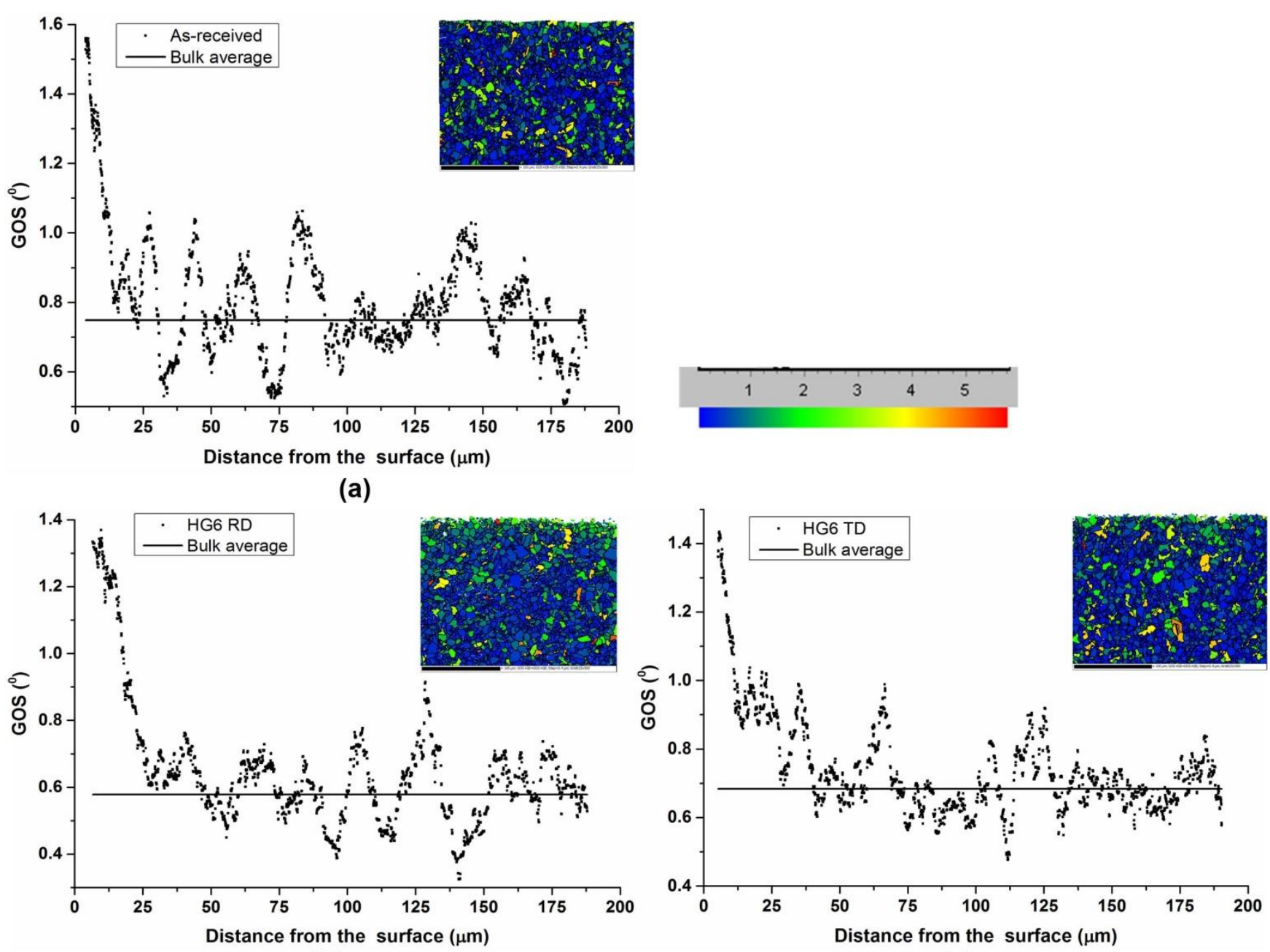

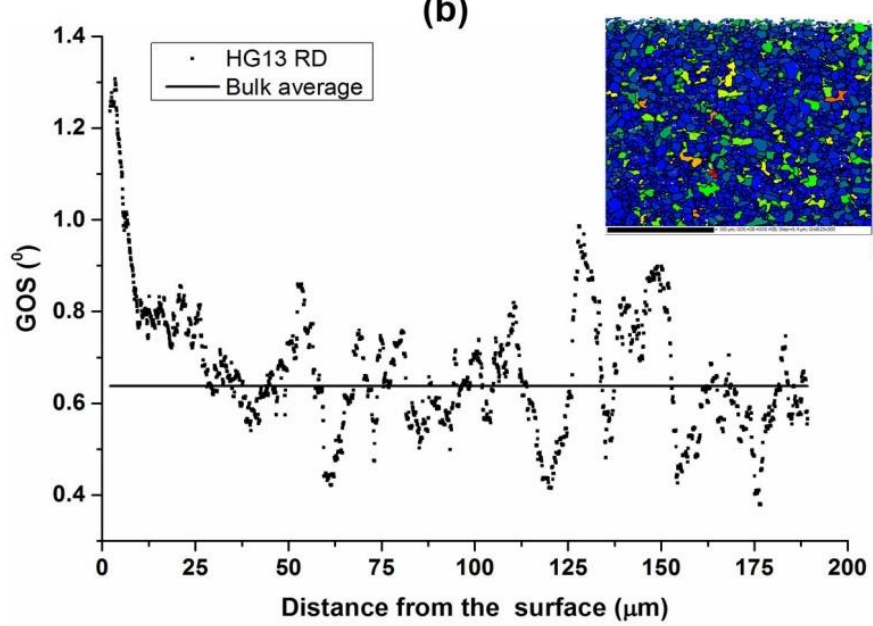

(d)

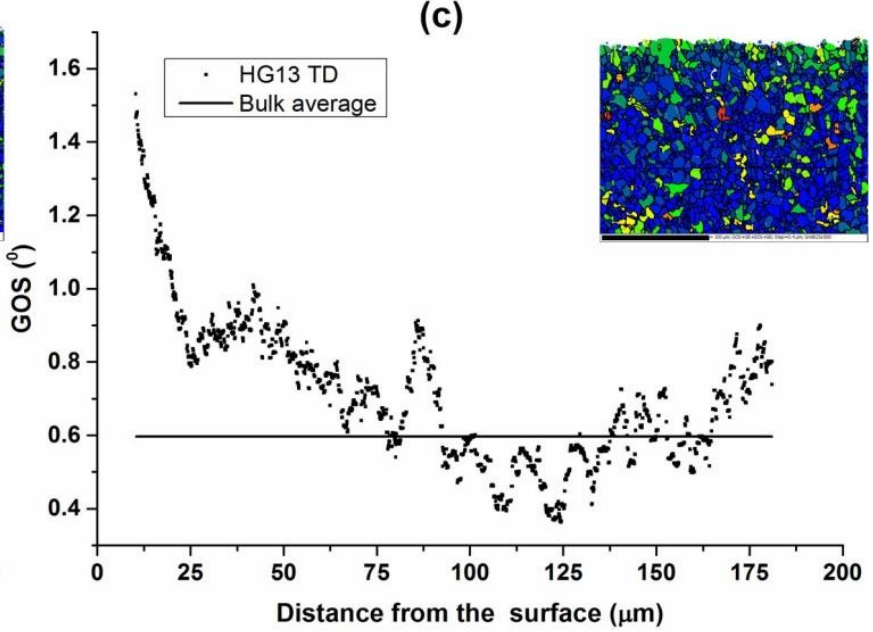

(e)

2 Fig. 12. Comparison of GOS profiles measured by EBSD before and after DCR of RR1000: (a) asreceived, (b, c) DCR using HG6 along RD and TD (d, e) DCR using HG13 along RD and TD 
1 The effect of plastic deformation by DCR can be investigated using misorientation angle of the 2 individual measurement points collected through EBSD scanning. Fig. 12 compares Grain Orientation 3 Spread (GOS) maps and the moving average of GOS along the depth before and after DCR. GOS 4 assigns a single value for each grain, determined by the average deviation in orientation between every 5 pixel and the average grain orientation. The work hardening zone is characterized as the depth at which 6 the moving average of GOS intersects the bulk GOS, as explained earlier in section 2. The as-received 7 samples are found to have few grains with high GOS close to the surface within $22 \mu \mathrm{m}$ depth (Fig. 8 12a). This behavior matches with the corresponding high hardness and compressive residual stresses 9 for the as-received RR1000 at the regions closer to the surface (Figs. 3b and 4b). It is obvious from Fig. 12 that the work hardening zone increased after DCR. The samples after DCR with HG6 ball obtained 11 a deformation depth ranging between 40 and $46.5 \mu \mathrm{m}$ (Fig. 12b and 12c). Samples rolled with HG13 ball resulted in a deeper hardened zone, with a higher amount of grains having the misorientation larger than the bulk average. The work hardening layer was as deep as $78 \mu \mathrm{m}$ along the transverse direction with HG13 ball. Though the work hardening layer estimated from the GOS analysis comprises of highly deformed grains, it can be observed from Fig. 12 that few grains with a higher misorientation also exist in the bulk of the material for all sample conditions.

17 The deformation gradient within a grain can be analyzed using their local misorientation profiles (Fig. 13), which calculates the average misorientation of each pixel with its surrounding pixels, highlighting the intragranular misorientation. In comparison with the as-received sample (Fig. 13a), the misorientation within the grains appears to be more uniform after rolling (Fig. 13b to 13d). It is evident that the heavily deformed grains at the near-surface layer have higher misorientation, with lesser intragranular variation. The grains along the rolling direction indicate signs of slight elongation (Fig. 13d) for HG13 ball whereas the transverse direction experiences deeper penetration (Fig. 13e). Similar to IN100, the region very close to the surface $(\sim 5 \mu \mathrm{m})$ could not be indexed by EBSD for RR1000, especially after DCR with HG13 ball. As mentioned in section 3.4.1, the inability to index the 
(b)

(a)

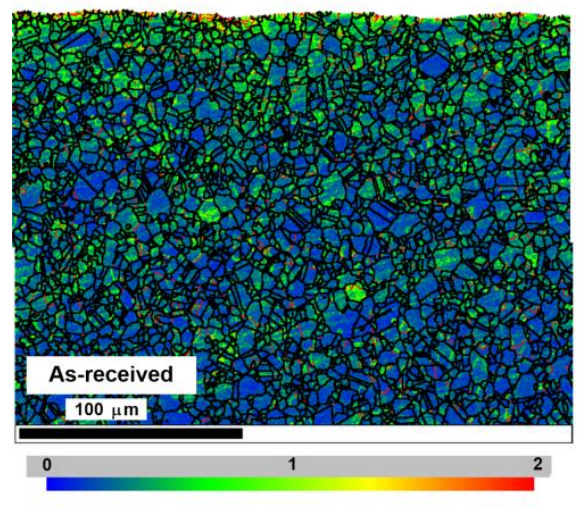

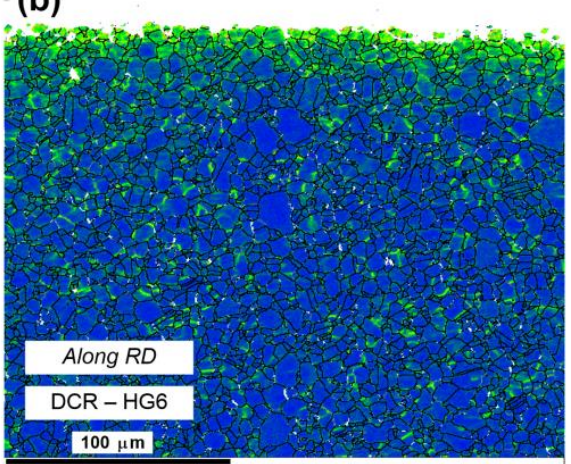

(d)

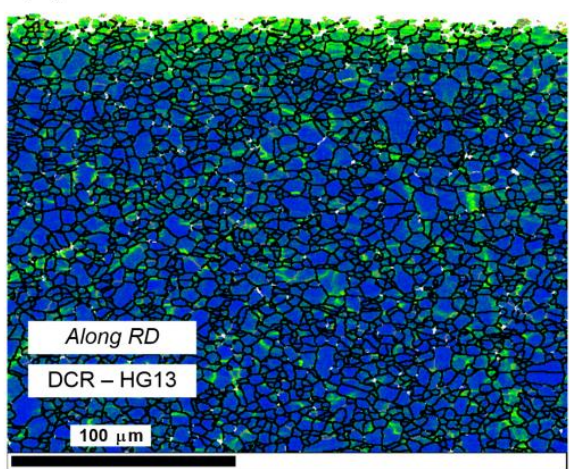

(c)

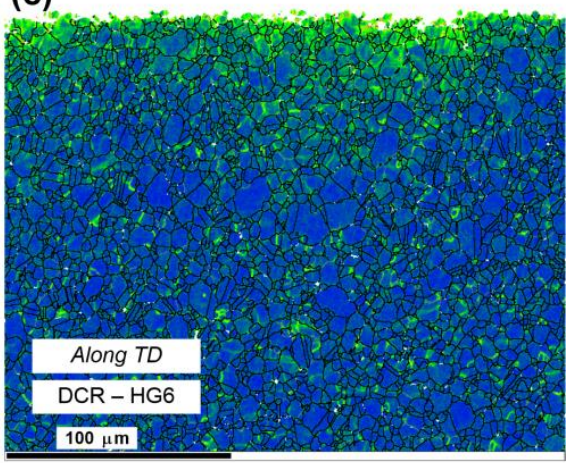

(e)

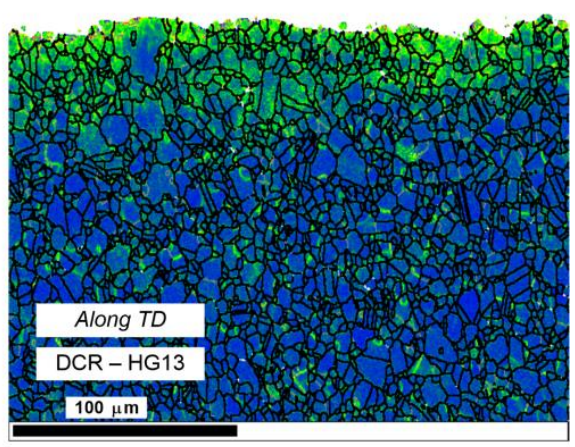

Fig. 13. Comparison of local misorientation maps of RR1000 between (a) as-received and after DCR

(b) and (d) along the rolling direction (c) and (e) along the transverse direction

The effect of work hardening can also be analyzed using FWHM of the X-ray diffraction peaks. Fig. 14 compares the FWHM of the X-ray peaks between the as-received and rolled samples. It is obvious from Fig. 14 that the maximum work hardening occurred at the surface for the as-received and the rolling conditions. FWHM profile of the as-received samples along the depth correlate well with the corresponding hardness results (Fig. 3b), confirming the pre-existing work hardening till $100 \mu \mathrm{m}$. In comparison to the as-received RR1000, the rolled samples resulted in an increased FWHM for depths after $50 \mu \mathrm{m}$ despite a similar FWHM levels at the surface. It is interesting to observe that the FWHM is identical for all the rolled samples till the depth of $25 \mu \mathrm{m}$. However, FWHM decreases sharply to the as-received FWHM at around $250 \mu \mathrm{m}$ for DCR with HG6 ball before it plateaus. Compared to HG6, DCR with HG13 ball resulted in higher degree of work hardening, as seen from the consistently higher FWHM at Fig. 14. The FWHM with the HG13 gradually decreased to the as-received FWHM at 400 $\mu \mathrm{m}$ depth. No change in FWHM values between the rolling and transverse directions was observed despite the change in ball diameter. The average FWHM at the bulk of the as-received RR1000 is around $2.25^{\circ}$, which is illustrated as the dotted lines in Fig. 14 along with its standard deviation. The 
1 work hardening depth after DCR is approximated as the depth at which the FWHM of the DCR 2 samples converges with the bulk FWHM. By comparing the FWHM of as-received and rolled 3 conditions from Fig. 14, the work hardening or cold worked depth are estimated to be 250 and $400 \mu \mathrm{m}$ 4 after DCR with HG6 and HG13 balls, respectively. Comparison of the residual stress and FWHM 5 profiles highlights that the depth of work hardening $(250 \sim 400 \mu \mathrm{m})$ is less than half of the residual 6 stress depths $(700 \sim 1 \mathrm{~mm})$ approximately. This behavior matches with the previous research works on 7 other mechanical surface treatments of Ni-based alloys [12].

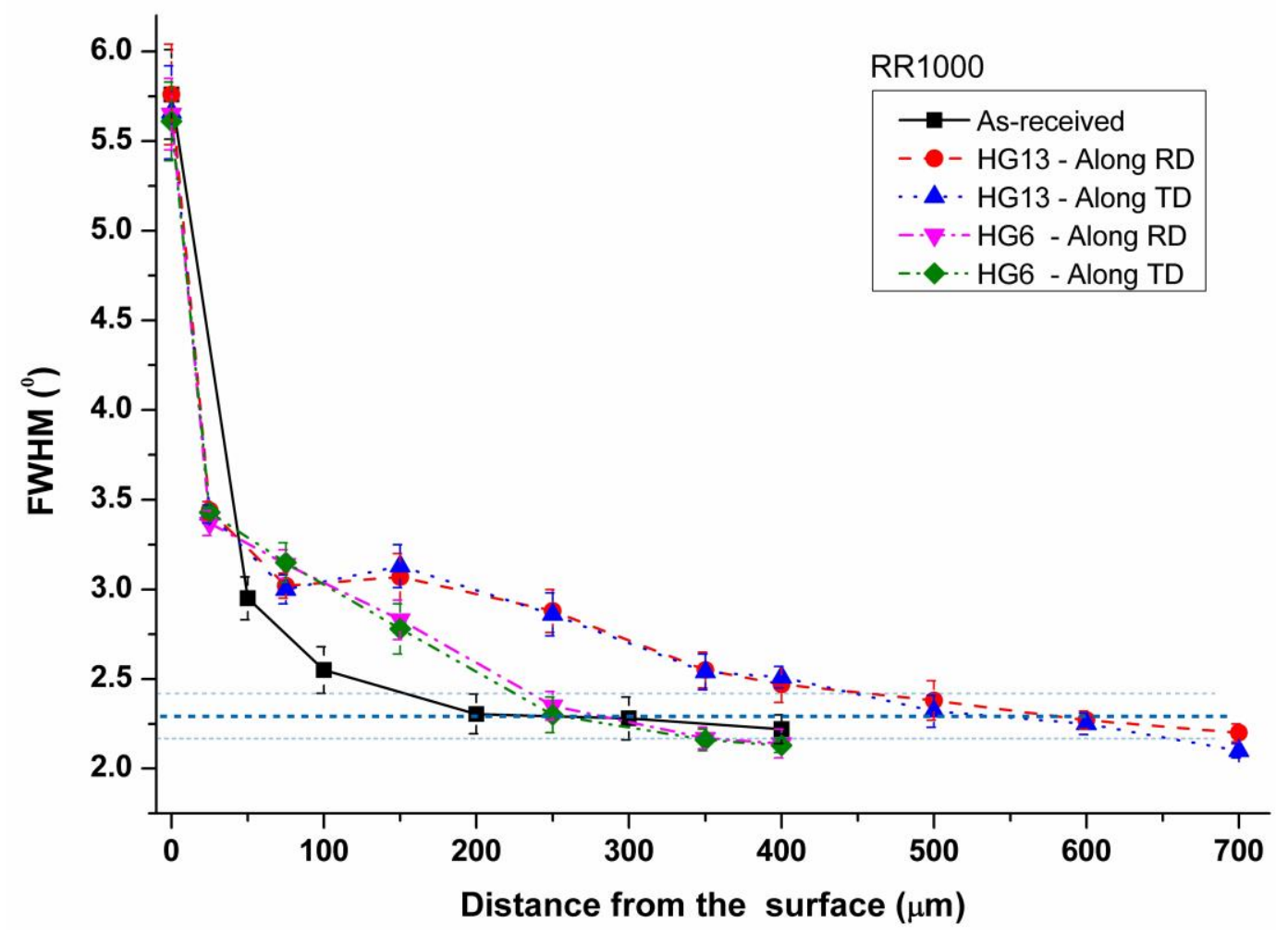

Fig. 14. Effect of DCR on FWHM of X-ray diffraction peak of RR1000 along the depth

10 Fig. 15 summarizes the effect of DCR on the work hardening and residual stress distribution at the 11 sub-surface, the hardness, residual stress and FWHM along the depth of the rolled samples. A sharp 12 reduction in hardness can be noted at $50 \mu \mathrm{m}$, the depth within which heavily deformed grains were 13 detected by the EBSD analysis. A similar high gradient in the degree of cold work is also evident from 14 the FWHM values at $50 \mu \mathrm{m}$. Hardness, FWHM and GOS results generally indicate a severe 15 deformation in the near-surface regions after DCR. Messe et al. [8] observed high dislocation density 16 regions, subgrain formation and high grain rotation with RR1000 after shot peening. 
1 After DCR by HG6 ball, both the hardness and FWHM were found to decrease steeply till $50 \mu \mathrm{m}$ from 2 the surface, before gradually reducing along the depth (Fig. 15b). This correlation could indicate the 3 larger influence of work hardening, especially the increase of dislocation density, on the hardness 4 measurements with RR1000, as opposed to the effect of residual stresses on the IN100 hardness. As the 5 hardness measurements have complex interaction with the residual stresses, microstructure changes and 6 work hardening, it is difficult to segregate the behavior.
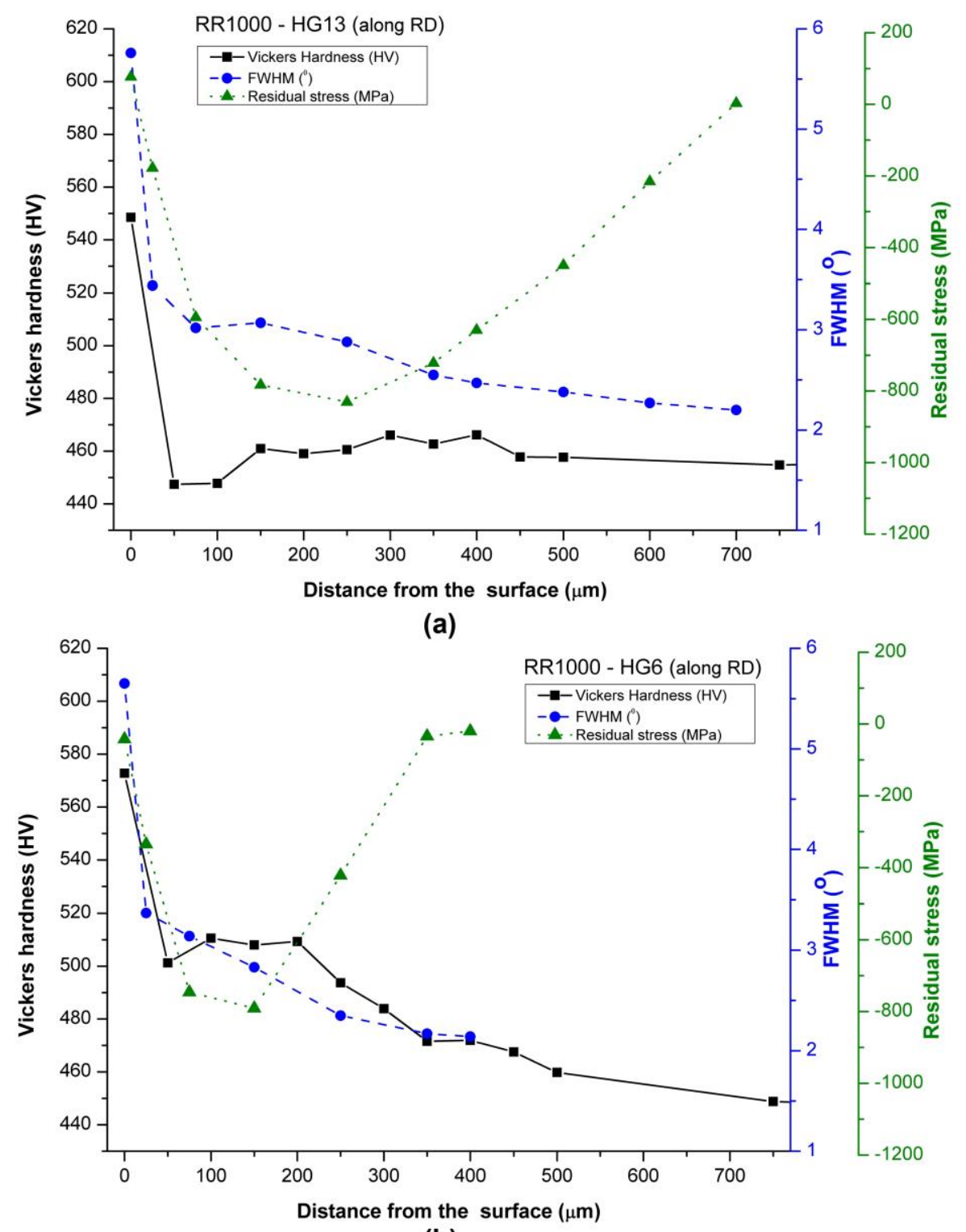

(b)

8 Fig. 15. Comparison of hardness, FWHM and residual stress along the depth of RR1000 after DCR (a)

HG13 (b) HG6 
1 The depth of work hardening zone calculated by the GOS profiles ranges between 40 to $80 \mu \mathrm{m}$ after

2 DCR. However, FWHM characterization by XRD estimates the work hardening layer in the range of 3250 to $400 \mu \mathrm{m}$, depending on the ball diameter. The discrepancy between the two methodologies could 4 be explained by the underlying measurement principles. X-ray peak broadening (FWHM) is a factor of microstresses in a crystallite, which is affected by the increase in dislocation density during cold working through increased average microstrain and reduced crystallite size. Though EBSD method can estimate the average intergranular (GOS) and intragranular (LM) misorientation profiles in addition to the grain size distribution, the information on the dislocation density is difficult to be extracted. Foss et al. [6] attributed the underestimation of work hardening depth by EBSD to two factors: (a) reduction in the average GOS at the regions closer to the surface as EBSD patterns could not be indexed due to the severe deformation, (b) the inability of EBSD to resolve zero and low-angle misorientations accurately makes the technique difficult to differentiate between low and no deformation regions. In addition, the bulk GOS was calculated by averaging the GOS of grains exist between 100 to $200 \mu \mathrm{m}$, due to the inability to scan a large area with EBSD. The grains at this depth clearly experience work hardening, as evident from the XRD and hardness results. As the baseline GOS is shifted, an underestimation of the work hardening depth can be expected. Another possible explanation for the difference between XRD and EBSD results has been the XRD measurement error due to the subsurface gradient within the material. The stresses measured by XRD technique is actually an exponentially weighted average of the stresses within the corresponding probe volume. Though the penetration depth of the X-ray beam is only about $5 \mu \mathrm{m}$ for Nickel-based alloys [44], presence of any stress gradient within the depth can lead to significant errors. A gradient in stress levels and hence interplanar spacing will potentially lead to a peak broadening. Since, no corrections were performed in this study, an overestimation of FWHM values and hence the work hardening depth by XRD technique are highly possible. Furthermore, the inability of EBSD to segregate the different phases with high coherency, like $\gamma$ matrix and $\gamma^{\prime}$ phase in RR1000, makes it difficult to understand the deformation of different phases and their interaction with the dislocation density during the deformation. The above-mentioned factors can be associated for the underestimation of work hardening zone by EBSD. In order to understand the detailed plastic deformation behavior of RR1000 during deep cold rolling, further analysis with TEM is required. 


\section{Conclusions}

This paper investigated the influence of deep cold rolling on two nickel-based superalloys, IN100 and RR1000, using two different rolling ball diameters. In order to understand the effect on the mechanical properties, the hardness and residual stress distribution along the depth were analyzed. The microstructure changes after DCR was characterized quantitatively and qualitatively using EBSD analysis. The following conclusions can be deduced from the results:

- DCR of IN100 demonstrated that compressive residual stresses and an increase in hardness as deep as $1 \mathrm{~mm}$ could be introduced during the process. A good correlation observed between the hardness profile and the residual stress distribution of IN100 along the depth after DCR indicates the dominance of compressive residual stresses on the hardness of the material, rather than the work hardening. The coarser grains of IN100 were found to be compressed into a layer of $50 \mu \mathrm{m}$ with significant grain refinement and high misorientation angle. An increase in low angle grain boundaries and their clustering around the carbides after DCR represent the work hardening induced dislocation density movement and multiplication.

- DCR of fine grain RR1000 induced compressive stresses till the depth of $700 \mu \mathrm{m}$, depending upon the ball diameter. The work hardening depth was 250 and $400 \mu \mathrm{m}$ for HG6 and HG13 balls respectively. EBSD analysis revealed the existence of highly deformed grains till the depth of 40 to $80 \mu \mathrm{m}$ using GOS profiles. A similar behavior was also observed with the hardness and FWHM values. After DCR of RR1000, the hardness measurement has good correlation with the FWHM characterization for the deep cold rolled RR1000 samples, indicating the effect of work hardening on the hardness measurements. The smaller discrepancy between hardness and FWHM for HG13 was attributed due to the severe deformation of the near-surface regions.

- The larger ball diameter generally induces higher plastic deformation with severely deformed layers and grain refinement at near-surface, leading to higher and deeper penetration of compressive stresses and work hardening but with a reduced surface stresses.

\section{Acknowledgements}

This work was conducted within the Rolls-Royce@NTU Corporate Lab with support from the National Research Foundation (NRF) Singapore under the Corp Lab@University Scheme. 


\section{References}

[1] M.J. Donachie, S.J. Donachie, Superalloys - A Technical Guide (2nd Edition), ASM International (2002).

[2] K.V. Jata, A. Roy, T.A. Parthasarathy, Failure Modes of Aerospace Materials, Encyclopedia of Structural Health Monitoring, John Wiley \& Sons, Ltd (2009).

[3] P. Withers, H. Bhadeshia, Residual stress. Part 2-Nature and origins, Materials Science and Technology 17(4) (2001) 366-375.

[4] I. Altenberger, Alternative Mechanical Surface Treatments: Microstructures, Residual Stresses \& Fatigue Behavior, Shot Peening, Wiley-VCH Verlag GmbH \& Co. KGaA (2006) 419-434.

[5] V. Schulze, J.K. Schwing, Modern mechanical surface treatment : states, stability, effects, Weinheim : Wiley-VCH (2005).

[6] B.J. Foss, S. Gray, M.C. Hardy, S. Stekovic, D.S. McPhail, B.A. Shollock, Analysis of shotpeening and residual stress relaxation in the nickel-based superalloy RR1000, Acta Materialia 61(7) (2013) 2548-2559.

[7] R. John, D.J. Buchanan, M.J. Caton, S.K. Jha, Stability of shot peen residual stresses in IN100 subjected to creep and fatigue loading, Procedia Engineering 2(1) (2010) 1887-1893.

[8] O.M.D.M. Messé, S. Stekovic, M.C. Hardy, C.M.F. Rae, Characterization of Plastic Deformation Induced by Shot-Peening in a Ni-Base Superalloy, JOM 66(12) (2014) 2502-2515.

[9] Turnbull, R. De Los, Tait, Laurant, Boabaid, Improving the fatigue crack resistance of Waspaloy by shot peening, Fatigue \& Fracture of Engineering Materials \& Structures 21(12) (1998) 1513-1524. [10] M. Blodgett, P. Nagy, Eddy Current Assessment of Near-Surface Residual Stress in Shot-Peened Nickel-Base Superalloys, Journal of Nondestructive Evaluation 23(3) (2004) 107-123.

[11] Y. Shen, C. Lee, C.C.H. Lo, N. Nakagawa, A.M. Frishman, Conductivity profile determination by eddy current for shot-peened superalloy surfaces toward residual stress assessment, Journal of Applied Physics 101(1) (2007) 014907.

[12] D.J. Child, G.D. West, R.C. Thomson, Assessment of surface hardening effects from shot peening on a Ni-based alloy using electron backscatter diffraction techniques, Acta Materialia 59(12) (2011) 4825-4834.

[13] R. Chandrasekar, A.M. Frishman, B.F. Larson, C.C.H. Lo, N. Nakagawa, Effects of Microstructure on Eddy Current Residual Stress Characterization of Shot-Peened Inconel 718, JOM 64(2) (2012) 257-264.

[14] P. Prevéy, J. Telesman, T. Gabb, P. Kantzos, FOD resistance and fatigue crack arrest in low plasticity burnished IN718, Proceedings of the 5th Nat. Turbine Eng. HCF Conference, 2000. [15] A.H. Clauer, Laser shock peening for fatigue resistance, Surface Performance of Titanium, JK Gregory, et al, Editors, TMS Warrendale, PA (1996) 217-230.

[16] A. Gill, A. Telang, S.R. Mannava, D. Qian, Y.-S. Pyoun, H. Soyama, V.K. Vasudevan, Comparison of mechanisms of advanced mechanical surface treatments in nickel-based superalloy, Materials Science and Engineering: A 576 (2013) 346-355.

[17] L.N. López de Lacalle, A. Lamikiz, J.A. Sánchez, J.L. Arana, The effect of ball burnishing on heat-treated steel and Inconel 718 milled surfaces, The International Journal of Advanced Manufacturing Technology 32(9) (2007) 958-968. [18] A. Sequera, C.H. Fu, Y.B. Guo, X.T. Wei, Surface Integrity of Inconel 718 by Ball Burnishing, Journal of Materials Engineering and Performance 23(9) (2014) 3347-3353. [19] I. Altenberger, Deep rolling - the past, the present and the future, Proceedings of 9th International Conference on Shot Peening, 2005, pp. 6-9.

[20] S. Mader, F. Klocke, Fundamentals of the deep rolling of compressor blades for turbo aircraft enginees, Modelling and simulation, Conf Proc: ICSP-9, Citeseer, 2005, pp. 125-130. 
1 [21] R.K. Nalla, I. Altenberger, U. Noster, G.Y. Liu, B. Scholtes, R.O. Ritchie, On the influence of mechanical surface treatments - deep rolling and laser shock peening - on the fatigue behavior of $\mathrm{Ti}-$ 6Al-4V at ambient and elevated temperatures, Materials Science and Engineering: A 355(1-2) (2003) 216-230.

[22] L. Wagner, Mechanical surface treatments on titanium, aluminum and magnesium alloys, Materials Science and Engineering: A 263(2) (1999) 210-216.

[23] P. Delgado, I.I. Cuesta, J.M. Alegre, A. Díaz, State of the art of Deep Rolling, Precision Engineering 46 (2016) 1-10.

[24] I. Nikitin, I. Altenberger, Comparison of the fatigue behavior and residual stress stability of lasershock peened and deep rolled austenitic stainless steel AISI 304 in the temperature range $25-600^{\circ} \mathrm{C}$, Materials Science and Engineering: A 465(1) (2007) 176-182.

[25] S. Mader, F. Klocke, Fundamentals of the Deep Rolling of Compressor Blades for Turbo Aircraft Engines, Modelling and simulation, Conf Proc: ICSP-9, 2005, pp. 125-130.

[26] A. Bozdana, N. Gindy, Comparative experimental study on effects of conventional and ultrasonic deep cold rolling processes on Ti-6Al-4V, Materials Science and Technology 24(11) (2008) 13781384.

[27] C.C. Wong, A. Hartawan, W.K. Teo, Deep Cold Rolling of Features on Aero-Engine Components, Procedia CIRP 13 (2014) 350-354.

[28] A. Lim, S. Castagne, C. Cher Wong, Effect of Deep Cold Rolling on Residual Stress Distributions Between the Treated and Untreated Regions on Ti-6Al-4V Alloy, Journal of Manufacturing Science and Engineering 138(11) (2016) 111005-111005-8.

[29] G. Majzoobi, K. Azadikhah, J. Nemati, The effects of deep rolling and shot peening on fretting fatigue resistance of Aluminum-7075-T6, Materials Science and Engineering: A 516(1) (2009) 235247.

[30] B. Nagarajan, S. Castagne, Microstructure Study of Nickel-Based Superalloys after Deep Cold Rolling, Materials Science Forum, Trans Tech Publ, 2017, pp. 169-174.

[31] D. Trauth, F. Klocke, P. Mattfeld, A. Klink, Time-efficient Prediction of the Surface Layer State after Deep Rolling using Similarity Mechanics Approach, Procedia CIRP 9 (2013) 29-34.

[32] S.A. Croxall, M.C. Hardy, H.J. Stone, P.A. Midgley, The Microstructure of RR1000 Nickel-Base Superalloy: The FIB-SEM Dual-Beam Approach, 1st International Conference on 3D Materials Science, John Wiley \& Sons, Inc. 2012, pp. 215-220.

[33] J. Pang, M. Preuss, P. Withers, G. Baxter, C. Small, Effects of tooling on the residual stress distribution in an inertia weld, Materials Science and Engineering: A 356(1-2) (2003) 405-413. [34] Prevéy, The effect of cold work on the thermal stability of residual compression in surface enhanced IN718, LAMBDA RESEARCH CINCINNATI OH, 2000.

[35] G.S. Schajer, Measurement of Non-Uniform Residual Stresses Using the Hole-Drilling Method. Part I-Stress Calculation Procedures, Journal of Engineering Materials and Technology 110(4) (1988) 338-343.

[36] S. Birosca, F. Di Gioacchino, S. Stekovic, M. Hardy, A quantitative approach to study the effect of local texture and heterogeneous plastic strain on the deformation micromechanism in RR1000 nickelbased superalloy, Acta Materialia 74(0) (2014) 110-124.

[37] R. Yoda, T. Yokomaku, N. Tsuji, Plastic deformation and creep damage evaluations of type 316 austenitic stainless steels by EBSD, Materials Characterization 61(10) (2010) 913-922.

[38] S.I. Wright, M.M. Nowell, D.P. Field, A Review of Strain Analysis Using Electron Backscatter Diffraction, Microscopy and Microanalysis 17(3) (2011) 316-329.

[39] A.J. Wilkinson, G. Meaden, D.J. Dingley, High resolution mapping of strains and rotations using electron backscatter diffraction, Materials Science and Technology 22(11) (2006) 1271-1278. 
1 [40] D.T. Ardi, W. Wei, I. Parr, G. Feldmann, A. Aramcharoen, C.C. Wong, Investigations of the 2 Residual Stresses and Surface Integrity Generated by a Novel Mechanical Surface Strengthening, 3 Materials Research Proceedings 2 (2017) 311-316.

4 [41] A.M. Hassan, A.M. Maqableh, The effects of initial burnishing parameters on non-ferrous 5 components, Journal of Materials Processing Technology 102(1-3) (2000) 115-121.

6 [42] F. Klocke, V. Bäcker, H. Wegner, B. Feldhaus, H.-U. Baron, R. Hessert, Influence of process and 7 geometry parameters on the surface layer state after roller burnishing of IN718, Production Engineering 8 3(4) (2009) 391.

9 [43] M. Sayahi, S. Sghaier, H. Belhadjsalah, Finite element analysis of ball burnishing process:

10 comparisons between numerical results and experiments, The International Journal of Advanced

11 Manufacturing Technology 67(5) (2013) 1665-1673.

12 [44] P.S. Prevey, X-ray diffraction residual stress techniques, ASM International, ASM Handbook. 10 13 (1986) 380-392. 